\section{Ankara Üniversitesi Eğitim Bilimleri Fakültesi Özel Eğitim Dergisi}

2022, 23(3), 613-636
ARAŞTIRMA

Gönderim Tarihi: 15.12 .20

Kabul Tarihi: 22.11.21

Erken Görünüm: 12.01.22

\title{
Öğrenme Güçlüğü Olan Öğrencilere Alışveriş Problemleri Çözme Becerisinin Kazandırılması ve Günlük Yaşama Genellenmesi
}

\author{
Samed Yenioğlu $(i D$
}

\author{
Kübra Sayar ${ }^{(D 2}$
}

\author{
Nevin Güner-Yıldız ${ }^{(i D}$
}

$\ddot{O} \mathbf{z}$

Giriş: Günlük yaşamda matematik becerilerine sıklıkla gereksinim duyulmaktadır. Matematik, zamanı öğrenmede, alışveriş yapmada, çalışma hayatında, hatta çocukların oynadığı oyunlarda bile karşımıza çıkmaktadır. Matematiğin günlük yaşamdaki önemi temel matematik becerilerinin özel gereksinimi olanlar da dâhil olmak üzere tüm bireylere kazandırılmasını zorunlu kılmaktadır. Özellikle para kavramını ve paranın nasıl harcanacağını öğretmek öğrenme güçlüğü olan öğrencilerin başkalarına bağımlı olmadan yaşamlarını sürdürebilmeleri için oldukça önemlidir. Bu araştırmada, doğrudan öğretim yöntemi kullanılarak verilen eğitimin genel eğitim okullarındaki öğrenme güçlüğü olan öğrencilerin alışveriş yapmada kullanılan işlemlerden oluşan matematik problemlerini çözme becerisini kazanma ve bu beceriyi günlük yaşamda alışveriş yaparken kullanmaları üzerindeki etkililiği incelenmiştir.

Yöntem: Bu araştırma, tek denekli araştırma modellerinden katılımcılar arası yoklama evreli çoklu yoklama modeline göre desenlenmiştir. Çalışmanın katılımcıları, Eskişehir'de devlet okullarında kaynaştırma/bütünleştirme yoluyla eğitime devam eden ve bir özel eğitim ve rehabilitasyon merkezinden destek eğitim alan 10-12 yaş aralığında üç erkek öğrenciden oluşmaktadır.

Bulgular: Araştırmada katılımcılara doğrudan öğretim yöntemi ile alışveriş yaparken kullanılan işlemlerden oluşan matematik problemlerini çözme becerisi öğretilmiş ve katılımcıların öğrendikleri beceriyi bir markette alışveriş yaparken kullanma düzeyleri değerlendirilmiştir. Araştırma sonucunda elde edilen bulgulara göre katılımcı öğrenciler alışveriş yapmada kullanılan işlemleri içeren problemleri çözme becerisini kazanmış ve bu beceriyi market alışverişinde kullanarak günlük yaşamlarına genelleyebilmiştir.

Tartışma: Araştırmanın bulguları, alanyazında yer alan ve özel gereksinimi olan öğrencilere matematik becerilerinin öğretimini inceleyen araştırmaların sonuçlarıyla tutarlıdır. Elde edilen sonuçlar benzer araştırmalarla karşılaştırılarak tartışılmıştır.

Anahtar sözcükler: Alışveriş yapma becerisi, günlük yaşam becerisi, problem çözme, matematik öğretimi, doğrudan öğretim yöntemi, öğrenme güçlüğü.

Atıf için: Yenioğlu, S., Sayar, K., \& Güner-Yıldız, N. (2022). Öğrenme güçlüğü olan öğrencilere alışveriş̧ problemleri çözme becerisinin kazandırılması ve günlük yaşama genellenmesi. Ankara Üniversitesi $\begin{array}{lllll}\text { Eğitim Bilimleri Fakültesi Özel Eğitim Dergisi, } & \text { 23(3), 613-636 }\end{array}$ https://doi.org/10.21565/ozelegitimdergisi.841368

\footnotetext{
1Sorumlu Yazar: Uzman, Eskişehir Osmangazi Üniversitesi, E-posta: samedyenioglu@ gmail.com, https://orcid.org/00000002-2227-9132

${ }^{2}$ Uzman, Eskişehir Osmangazi Üniversitesi, E-posta: kubrasayar87@gmail.com, https://orcid.org/0000-0003-0901-3660

${ }^{3}$ Doç. Dr., Eskişehir Osmangazi Üniversitesi, E-posta: antreh@gmail.com, https://orcid.org/0000-0002-9135-6429
} 


\section{Giriş}

Günlük yaşamda matematik becerilerine sıklıkla gereksinim duyulmaktadır. Matematik, zamanı öğrenmede, alışveriş yapmada, çalışma hayatında, hatta çocukların oynadığı oyunlarda bile karşımıza çıkmaktadır (Bouck \& Flanagan, 2009; Gobadze \& Düzkantar, 2019). Bu nedenle matematik becerileri yaşamımızı bağımsız bir şekilde sürdürebilmemiz için öğrenilmesi gereken becerilerdir (Tufan vd., 2020). İlkokul ve ortaokul matematik dersi öğretim programında yer alan amaçlar incelendiğinde; akıl yürütme, matematik dilini kullanarak iletişim kurma, tahminde bulunma, matematiksel kavramları anlayabilme ve bunları günlük yaşamda kullanma gibi temel amaçların bulunduğu görülmektedir (Millî Eğitim Bakanlığı [MEB], 2018). Programda yer alan ve kazandırılması amaçlanan matematiksel beceriler birbirleriyle bağlantılı ve birbirine ön koşul becerilerdir. Problem çözme becerisi de matematik öğretim programının temel amaçları arasında yer almaktadır (National Council of Teachers of Mathematics [NCTM], 2000). Problem çözme, öğrencilerin matematik programında yer alan birçok kavram ve beceriyi uygulamaya koymalarını gerektiren önemli bir matematiksel beceridir (Bağlama, 2018). Altun (2000), problemleri rutin ve rutin olmayan problemler olarak iki sınıfa ayırmaktadır. Dört işlemden biri ya da birkaçını içeren problemler rutin problemler olarak tanımlanmaktadır. Öğrencilerin verileri analiz ederken birden fazla strateji kullanmasını ve yaratıcı girişimde bulunmasını gerektiren problemler ise rutin olmayan problemler olarak tanımlanmaktadır (Artut \& Tarım, 2006). Rutin olmayan problemlerin amacı, problem çözmenin mantığının kavranması ve problem için uygun stratejinin seçilmesidir (Altun, 2000, 2016). Rutin problemlerin temel amacı ise günlük yaşamda kullanılan işlem becerilerinin geliştirilmesi, problemde yer alan bilgilerin matematik eşitliklerine dönüştürülmesi, dönüştürülen eşitlikler aracılığıyla düşüncelerin modellenmesi ve problem çözmek için kullanılan temel becerilerin kazandırılmasıdır (Altun, 2016). Problem çözme sürecinde say1, sembol ve işaret gibi matematiksel bilgiyi anlama ve bu bilgiler arasında ilişki kurma becerisi gelişmektedir (Yantır, 2007). Problem çözme becerisinin gelişmesiyle birlikte çocuklarda yaratıcı, eleştirel düşünme becerileri gelişmekte ve çocuklar analiz, sentez ve matematiksel düşünme becerilerini kullanmayı da öğrenmektedir (Olkun \& Toluk, 2009). Matematiksel beceri kazanan çocuklar günlük yaşamlarında örüntü ve düzenleri fark etmekte, kavramları ve bilimsel süreçleri daha kolay öğrenmektedir (Olkun \& Toluk, 2009). Matematiksel düşünme becerisi tipik gelişim gösteren çocukların olduğu kadar özel gereksinimi olan çocukların da yaşamlarında önemli yer tutmaktadır (Karabulut \& Yıkmış, 2016). Temel amacı bireylere bağımsız yaşam için gerekli becerileri kazandırmak olan eğitim süreci (Cooper vd., 2019) ile bu becerileri kazanmada tipik gelişim gösterenlere oranla daha yoğun ve hassas bir desteğe gereksinim duyan özel gereksinimi olan öğrencilere matematik becerilerini kazandırmak önemli ve gereklidir.

Özel eğitime gereksinim duyan grubun içerisinde yer alan öğrenme güçlüğü olan öğrencilere müdahale edilmesi gereken temel alanlardan biri de matematik becerileridir (Miller \& Mercer, 1997). Öğrenme güçlüğü olan öğrenciler sayıları tanımada, sayıları yazmada, temel işlemleri yapmada ve genel matematik terimleri hakkında güçlükler yaşamaktadır (Bryant vd., 2000; Kingsdorf \& Krawec, 2014). Bunların yanı sıra öğrenme güçlüğü olan öğrencilerin, okuma ve okuduğunu anlama becerilerinde yaşadıkları güçlükler, öğrencilerin matematik problemlerinde yer alan ekleme, çıkarma ya da ödünç verme gibi matematik terimlerini karıştırmalarına neden olmaktadır (Özkubat \& Özmen, 2018). Toplum içinde yaşayan her bireyin olduğu gibi öğrenme güçlüğü olan öğrencilerin de yeteneklerinin en üst düzeyde geliştirilmesi eğitimin öncelikli hedeflerinden olduğu için bu bireylerin eğitimlerinde de problem çözme süreci oldukça önemlidir (Kot \& Y1kmış, 2018). Temel matematik alanlarından biri olan problem çözme becerisi, öğrenme güçlüğü olan öğrencilerin matematikte zorlandıkları becerilerin başında gelmektedir (Montague \& Applegate, 1993). Öğrenme güçlüğü olan öğrencilerin problem çözerken yaşadıkları güçlükleri ortaya koymak amacıyla yapılan birçok çalışma bulunmaktadır (Montague \& Applegate, 1993; Ostad \& Sorensen, 2007; Özkubat \& Özmen, 2018; Rosenzweig vd., 2011; Shin \& Bryant, 2015; Swanson \& Jerman, 2006). Öğrenme güçlüğü olan öğrencilerin problem çözme becerilerinde özellikle problemin sunumuyla ilişkili süreçlerde ve strateji belirlemede güçlük yaşadıkları görülmektedir. $\mathrm{Bu}$ stratejiler, problemi kendi kelimeleriyle yeniden ifade etmeyi, problemi kâğıt üzerinde resimlerle görselleştirmeyi ve problemi çözmek için planlar oluşturmayı içermektedir. Bu nedenle öğrenme güçlüğü olan öğrencilere problem çözme becerisi kazandırılırken mutlaka açık bir yönerge verilerek öğretim yapılmalıdır (Montague \& Applegate, 1993). Matematik problemlerinin öğretimi sırasında aynı zamanda paylaştırma, gruplama, saat okuma ve alışveriş becerilerine yönelik öğretim de yapılabilmektedir. Özellikle para kavramını ve paranın nasıl harcanacağını öğretmek bu bireylerin yaşamlarını başkalarına bağımlı olmadan sürdürebilmeleri için oldukça önemlidir (Arı vd., 2010; Browder \& Grasso, 1999). Para kullanarak alışveriş yapma, temel işlem yapma becerisi yanında problem çözme becerisini de gerektiren bir beceri alanıdır (Mechling vd., 2003). Özel gereksinimi olan öğrenciler soyut ve karmaşık olan matematik becerilerini öğrenirken akranlarına göre daha fazla zorlandıkları için (Bouck \& Flanagan, 2009; Kroesbergen \& Van Luit, 2003) bu bireylere matematik problemlerini çözme becerisi öğretilirken 
somutlaştırma ve işlemin küçük basamaklara bölünmesini içeren etkili öğretim yöntem ve tekniklerinden yararlanılmalıdır.

Öğrenme güçlüğü olan öğrencilerin matematik problemi çözme becerisini geliştirmeye yönelik yapılan müdahale çalışmalarında farklı yöntem ve stratejilerin kullanıldığı görülmektedir. Bu çalışmalarda kullanılan yöntem ve stratejilerden bazıları doğrudan öğretim yöntemi, şemaya dayalı problem çözme stratejisi, somut-yarı somut-soyut stratejisi ve SOLVE stratejisi olarak siralanabilmektedir (Özkubat vd., 2021). Bu yöntem ve stratejilerin kullanıldığı çalışmalar incelendiğinde etkili sonuçlar elde edildiği görülebilmektedir. Örneğin Zawaiza ve Gerber (1993), doğrudan öğretim yönteminin öğrenme güçlüğü olan öğrencilerde sözel matematik problem çözme becerisini geliştirdiği belirtilmiş̧tir. Ayrıca araştırma sonucunda katılımcı öğrencilerin edindikleri beceriyi çalışma sona erdikten sonra da devam ettirdikleri ortaya konulmuştur. Diğer bir çalışmada Preston (2016), öğrenme güçlüğü olan öğrencilere tek aşamalı matematik problemlerinin çözümünün öğretiminde doğrudan öğretim yönteminin etkililiğini ortaya koymuştur. Ayrıca öğrencilerin edindikleri beceriyi ev ödevlerine ve sınıf içinde çözdükleri diğer problemlere genelleyebildikleri belirlemiştir. Bir başka çalışmada ise Small (2011) tarafından, matematik öğrenme güçlüğü olan öğrencilere sözel matematik problemi çözme öğretiminde doğrudan öğretim yönteminin etkili olduğu belirlenmiştir. Doğrudan öğretim yönteminin matematik problemi çözme becerisinin kazandırıldığı çalışmalarda tek başına bir yöntem olarak kullanılmasının yanı sıra bazı araştırmalarda bu yöntemin farklı bir stratejiyle birlikte sunulduğu görülmektedir. Örneğin Jitendra ve Hoff (1996), doğrudan öğretim yöntemiyle sunulan şemaya dayalı öğretim stratejisinin ilkokula devam eden ve öğrenme güçlüğ̈̈ olan üç öğrencinin problem çözme becerileri üzerindeki etkililiğini incelemişlerdir. Çalışma sonuçları tüm öğrencilerin problemleri doğru çözme oranlarında artış olduğunu göstermiştir. Ayrıca elde edilen kazanımların iki-üç hafta sonra da devam ettiği görülmüştür. Cass ve diğerleri (2003), öğrenme güçlüğü olan öğrencilere çevre ve alan problemlerinin çözümünün öğretiminde doğrudan öğretim ve somut-yarı somut-soyut stratejisini kullanmıştır. Araştırmacılar, müdahale sonucunda öğrencilerin beceriyi hızla edindiklerini, bu beceriyi iki ay boyunca sürdürdüklerini ve edindikleri becerileri kâğıt-kalem kullanarak problem çözme formatına aktardıklarını ortaya koymuştur. Öğrenme güçlüğü olan öğrencilere matematik problemi çözme becerisinin kazandırıldığı çalışmalarda doğrudan öğretim yöntemi dışında farklı yöntemlerin kullanıldığı çalışmalara bakıldığında, Jitendra ve diğerleri (2002) matematikte düşük performans gösteren öğrenme güçlüğü olan ortaokul öğrencileriyle şemaya dayalı problem çözme stratejisinin matematik problemi çözme becerisinin geliştirilmesi üzerindeki etkilerinin incelendiği tek denekli bir araştırma yapmıştır. Araştırmanın sonucunda tüm katılımcılarda matematik problemi çözme becerisinin geliştiğ i, öğrencilerin edindikleri becerileri sürdürdükleri ve öğrendikleri stratejileri farklı tür problemlere genelledikleri bulunmuştur. Bir başka çalışmada Hunt ve Vasquez (2014), matematik öğrenme güçlüğü olan öğrencilerde somut-yarı somut-soyut stratejisinin matematik problemi çözme öğretiminde etkililiğini araştırmış ve stratejinin etkili olduğunu ortaya koymuştur. Bunun yanı sıra Freeman-Green ve diğerleri (2015) tarafından yapılan araştırmada, öğrenme güçlüğü olan ortaokul öğrencilerine matematiksel kelime problemlerini çözmede yardımcı olmak için tasarlanmış anımsatıcı tabanlı bir öğrenme stratejisi olan SOLVE stratejisinin matematik problemi çözme becerileri üzerindeki etkileri incelenmiştir. Araştırma sonucunda katılımcıların tamamında doğru cevap sayısında artış olduğu gözlenmiştir. Ayrıca öğrencilerin öğrendikleri stratejiyi diğer matematik konularına genelledikleri bulgusu elde edilmiştir. Uluslararası alanyazında yapılan çalışmalarda öğrenme güçlüğü olan öğrencilerin problem çözme becerileri farklı yöntem ve stratejiler kullanılarak geliştirilmiştir. İncelenen araştırmalarda genelleme oturumları yalnızca kazanılan becerinin farklı problemlere genellenmesiyle sınırlı kalmış; öğrencilerin edindikleri problem çözme becerilerinin günlük yaşama genellenmesine yönelik bir bulguya rastlanmamıştır.

Türkiye'de özel gereksinimi olan öğrencilere matematik problemi çözme becerilerinin öğretiminin yapıldığı sınırlı sayıda çalışma olduğu görülmektedir. Bu çalışmalarda görme yetersizliği olan öğrencilere matematik problemi çözme becerisi doğrudan öğretim yöntemi ve şemaya dayalı problem çözme stratejisi ile kazandırılmıştı (Karakoç, 2002; Tuncer, 2009). Doğrudan öğretim yöntemi ve şemaya dayalı öğretim stratejisinin birlikte kullanıldığı bir başka çalışmada ise kullanılan stratejinin ortaokula devam eden zihin yetersizliği olan öğrencilerin matematik problemi çözme performansları üzerindeki etkisi araştııılmıştır. Çalışma sonucunda stratejinin etkili olduğu ve katılımcıların kazanılan beceriyi farklı ortam ve araç-gerece genelleyebildikleri ve 20 gün sonra da koruyabildikleri görülmüştür (Kot \& Yıkmış, 2018). Türkiye'de öğrenme güçlüğü olan öğrencilere yönelik matematik problemi çözme becerilerini desteklemek ve edindikleri becerileri günlük yaşamlarına genelleyebilmelerini sağlamak amacıyla doğrudan öğretim yöntemi ya da diğer yöntem/stratejilerin kullanıldığı bir müdahale çalışmasına rastlanmamıştır. 
Hem ulusal hem de uluslararası alanyazında gerçekleştirilen çalışmaların hiçbirinde problem çözme becerisinin günlük yaşama genellenmesinin incelenmediği görülmektedir. Oysa yaşamımızın birçok alanında para kullanımı, paylaştırma ve oran-orantı gibi matematik problemleri çözmeye gereksinim duyulmaktadır (Browder \& Grosso, 1999). Bundan dolayı matematik problemi çözme öğretiminin günlük yaşamla bağlantı kurularak verilmesi oldukça önemli görülmektedir. Ülkemizde matematik öğretim programlarının genel amaçları arasında öğrencilerin matematik kavramlarını anlamaları, kavramlar arası ilişki kurabilmeleri ve kavramları günlük yaşamda kullanabilmelerinin sağlanması yer almaktadır (MEB, 2018). Alanyazında öğrencilerin genellikle matematiği yaşamlarından bağımsız olarak gördükleri ve matematiğin günlük yaşamdaki yararını göremedikleri belirtilmektedir (Gainsburg, 2008; Sparrow, 2008). Öğretimin edinim aşamasının başlangıçta yapılandırılmış bir ortamda gerçekleştirilmesi gerekli olabilir ancak alanyazında bu öğretimin günlük yaşamla bağlantı kurularak gerçekleştirilmesinin daha iyi sonuçlar verdiği bildirilmektedir (Xin vd., 2005). Araştırmalarda matematik öğretiminin günlük yaşamla ilişkilendirilmesinin öğrencilerin matematiksel kavramları daha iyi anlamlandırmalarına ve matematiğe yönelik tutum ve motivasyonlarının artmasına yol açtığı vurgulanmaktadır (Albert \& Antos, 2000; Gainsburg, 2008).

Bu araştırmada öğrenme güçlüğü olan öğrencilere matematik problemi çözme becerisi doğrudan öğretim yöntemi kullanılarak kazandırılmaya çalışılmıştır. Doğrudan öğretim yönteminin uygulanmasının kolay olması, öğrencilere bağımsız uygulama olanağı sağlaması, edindikleri becerileri organize etmeye ve genellemeye yardımc1 olmasından dolayı (Carnine vd., 1997; Dağseven-Emecen, 2008) bu araştırmada doğrudan öğretim yöntemi tercih edilmiştir. Ulusal alanyazında, öğrenme güçlüğü olan öğrencilere matematik problemlerinin çözümünün öğretilmesine yönelik çalışmaların oldukça az olduğu görülmekle birlikte (Bağlama, 2018; Baki, 2014; Karabulut vd., 2015; Kot \& Y1kmış, 2018; Preston, 2016; Small, 2011) hem ulusal hem de uluslararası alanyazında bu öğrencilerin problem çözme becerisini geliştirerek bu beceriyi günlük yaşamlarına genellemelerinin incelendiği herhangi bir müdahale çalışmasına rastlanmamıştır. Bu araştırmanın, öğrenme güçlüğü olan öğrencilere doğrudan öğretim yöntemiyle matematik problemlerinin öğretildiği ilk çalışma olmasının yanı sıra öğretilen becerinin günlük yaşama genellenmesini de içeriyor olması nedeniyle önemli olduğu ve alana katkı sağlayacağı düşünülmektedir. Bu araştırmanın temel amacı, öğrenme güçlüğü olan öğrencilerin alışveriş yapmada kullanılan işlemleri içeren matematik problemlerini çözme becerisini kazanmalarını ve kazandıkları beceriyi günlük yaşamda kullanma düzeylerini incelemektir. Bu amaç doğrultusunda araştırmada şu sorulara yanıt aranmıştır:

1. Öğrenme güçlüğü olan öğrencilere, doğrudan öğretim yöntemiyle alışveriş yapmada kullanılan işlemlerden oluşan matematik problemlerinin çözümü öğretildiğinde öğrenciler beceriyi kazanabilmekte midir?

2. Katılımcı öğrenciler kazanılan beceriyi bir, iki ve üç hafta sonra sürdürebilmekte midir?

3. Katılımcı öğrenciler kazandıkları matematik problemi çözme becerilerini günlük yaşamda yaptıkları alışverişe genelleyebilmekte midir?

4. Araştırma öğrenme güçlüğü olan öğrenciler ve öğretmenleri için sosyal açıdan geçerli midir?

\section{Yöntem}

\section{Araştırma Modeli}

Genel eğitim okullarındaki öğrenme güçlüğü olan öğrencilerin alışveriş yapmada kullanılan işlemlerden oluşan matematik problemlerini çözme becerisini kazanma ve bu beceriyi günlük yaşama genellenmesinin incelendiği bu araştırmada, tek denekli araştırma modellerinden katılımcılar arası yoklama evreli çoklu yoklama modeli kullanılmıştır. Hem dış geçerliğin yüksek olması hem de iç geçerliği tehdit eden unsurları kontrol altına almanın daha kolay olması nedeniyle bu desen tercih edilmiştir (Tekin-İftar, 2012). Bu modelde, öğretim öncesi tüm katılımcılardan eş zamanlı olarak başlama düzeyi verisi alınır ve kararlı veri elde edildiğinde birinci katılımcıda öğretim oturumlarına başlanır. Birinci katılımcı ölçütü karşıladığında tüm katılımcılarda birinci toplu yoklama oturumu düzenlenir. Kararlı veri elde edildikten sonra ikinci katılımcıda öğretim oturumuna geçilir. İkinci katılımcı da ölçütü karşıladığında tüm katılımcılarla ikinci toplu yoklama oturumu gerçekleştirilir. Kararlı veri elde edildikten sonra üçüncü katılımcı ile öğretime geçilir ve üçüncü katılımcı ölçütü karşıladığında tüm katılımcılarla son toplu yoklama oturumu gerçekleştirilir ve uygulama sonlandırılır (Tekin-İftar, 2012).

\section{Çalışma Grubu}

Araştırmada yer alacak öğrencilerin genel eğitim okullarında kaynaştırma/bütünleştirme yoluyla eğitime devam ediyor olması ve görme-işitme yetersizliğinin bulunmaması yanında birtakım önkoşul becerilere sahip 
olması beklenmiştir. Bunlar; ifade edici dil becerisine sahip olma, öğretim sürecini takip edebilecek şekilde verilen uyarana en az beş dakika dikkatini yöneltebilme, yönerge takip becerisine sahip olma, okuma ve yazma bilme, rakamları ve sayıları okuyup yazabilme, parayı tanıma, iki basamaklı sayıla iki basamaklı sayıyı eldeli toplayabilme, iki basamaklı sayıdan iki basamaklı sayıı onluk bozmadan ve onluk bozarak çıarabilme, iki basamaklı sayıyla bir basamaklı sayıyı çarpabilme ve iki basamaklı sayıy bir basamaklı sayıya bölebilme becerileridir. Araştırmada yer alan tüm katılımcıların rehabilitasyon merkezindeki öğretmenleriyle öğrencilerin belirlenen ön koşul becerilere sahip olup olmadıkları hakkında görüşülmüş ve ayrıca öğrenciler ön koşul beceriler açısından birinci araştırmacı tarafından da gözlenmiştir. Yapılan görüşme ve gözlemlerin ardından katılımcıların sıralanan ön koşul becerilere sahip olduğu belirlenmiştir.

Çalışmanın katılımcıları, Eskişehir'de kaynaştırma/bütünleştirme yoluyla eğitim almakta olan ve bir özel eğitim ve rehabilitasyon merkezinde destek eğitim alan üç erkek öğrenciden oluşmaktadır. Katılımcı öğrencilerin demografik özellikleri Tablo 1'de özetlenmiştir. Tüm katılımcılar sağlık raporlarına göre öğrenme güçlüğü tanısına sahiptir. Tüm katılımcılar verilen sözel yönergeleri yerine getirir. Birer, ikişer, üçer, dörder, beşer, altışar, yedişer ve onar ritmik sayar. Temel okuma-yazma becerilerine sahiptir. Öz bakım becerilerini bağımsız olarak yerine getirebilir. Toplum ve sınıf kurallarına uyar. Market, manav vb. yerlerden yardım alarak alı̧̧veriş yapabilir. Katılımcıların rehabilitasyon merkezindeki özel eğitim öğretmenleriyle yapılan görüssme sonrasında, tüm katılımcıların dikkat sürelerinin ortalama 10-15 dakika olduğu bilgisi edinilmiştir.

Tablo 1

Katılımcı Özellikleri Tablosu

\begin{tabular}{|c|c|c|c|c|}
\hline İsim & Yaş & Sınıf düzeyi & Cinsiyet & Tan1 \\
\hline Burak & 10 & 5.sinif & Erkek & Öğrenme güçlüğü \\
\hline Kerem & 11 & 6.sinif & Erkek & Öğrenme güçlüğü \\
\hline Mehmet & 12 & 6.sinif & Erkek & Öğrenme güçlüğü \\
\hline
\end{tabular}

\section{Araştırmacılar}

Araştırmanın birinci yazarı, Özel Eğitim Bölümü Zihin Engelliler Öğretmenliği Lisans Programından mezun olmuş, özel eğitim alanında yüksek lisans yapmış ve yine aynı alanda doktora eğitimine devam etmektedir. Araştırmadaki uygulamaları yürüten birinci yazarın üç yıldan fazla özel eğitim öğretmenliği uygulama deneyimi bulunmaktadır. Araştırmanın ikinci yazarı ise Özel Eğitim Bölümü Zihin Engelliler Öğretmenliği Lisans Programından mezun olmuş aynı zamanda özel eğitim alanında yüksek lisans yapmıştır. Araştırmacının bir yıllık özel eğitim öğretmenliği uygulama deneyimi bulunmaktadır. Araştırmanın üçüncü yazarı özel eğitim alanında doktora derecesine sahiptir ve özel eğitim Bölümünde öğretim üyesi olarak çalışmaktadır.

\section{Ortam}

Araştırma, katılımcıların destek eğitim aldıkları özel eğitim ve rehabilitasyon merkezinde gerçekleştirilmiştir. Öğretim oturumlarının tamamı rehabilitasyon merkezinde bulunan Öğrenme Güçlüğü Bireysel-2 sınıfinda gerçekleşmiştir. Bu sınıfta iki masa, üç sandalye, iki kitaplık, bir malzeme dolabı, duvara sabitlenmiş beyaz yazı tahtası ve kitaplar bulunmaktadır. Araştırmanın genelleme oturumları ise katılımcıların devam ettikleri özel eğitim ve rehabilitasyon merkezinin yakınında bulunan bir süpermarkette gerçekleştirilmiştir. Süpermarkette yiyecek, içecek, manav, kasap, şarküteri ve kırtasiye bölümleri bulunmaktadır.

\section{Araç-Gereçler}

Araştırmada, öğretim ve yoklama oturumlarında öğrencinin soruları çözebileceği bir masa, oturabileceği bir sandalye, oturumları kaydetmek için ses kayıt cihazı, araştırma verilerini kaydetmek için kullanılan formlar, kalem, problemlerin yazılı olduğu çalışma kâğıdı, tahta ve tahta kalemi kullanılmıştır. Uygulama sürecinde kullanılmak üzere 120 soruluk bir soru havuzu hazırlanmıştır. Hazırlanan sorular MEB tarafından hazırlanan ve genel eğitim okullarında kullanılan kitaplarda yer alan sorular temel alınarak hazırlanmış ve uzman görüşü alınmıştır. Soru havuzundan rastgele seçilen sorularla hem öğretim hem de değerlendirme aşamasında kullanılmak üzere çalışma kâğıtları hazırlanmıștır. Hazırlanan çalışma kâğıtlarında öğrencilerin okuma hatalarını en aza indirmek için MEB kitaplarında kullanılan Alfabet98 yazı fontu ve 16 punto yazı büyüklüğü seçilmiş, dikkatlerini toplamak için uygun soru içerikleri hazırlanmıştır. Hazırlanan problem sorularında katılımcıların dikkatlerini çekebilecek mobil oyun karakterleri, çizgi film kahramanları, sevdikleri yiyecekler ya da eşyalar kullanılmıştır. Örneğin "Bakkaldan tanesi 3 TL olan 2 çikolatalı gofret, tanesi 2 TL olan 2 paket pokemon kartı ve tanesi 4 TL olan 2 bisküvi aldım. Bakkala 20 TL verirsem, bana kaç TL geri verir?" değerlendirme aracında yer alan 
problemlerden biridir. Ayrıca etkililik, güvenirlik ve genelleme verilerinin toplanabilmesi için hazırlanan veri toplama formu da çalışmanın araç-gereçleri arasındadır. Araştırmanın yapıldığı özel eğitim kurumunda görüntü kaydı yapılmasına izin verilmemesinden dolayı araştırma süresince sadece ses kaydı alınmıştır. Katılımcı öğrencilerin ailelerine araştırma süreciyle ilgili bilgi verilmiş ve ses kaydı yapılmasına yönelik yazılı izin alınmıştır.

\section{Bağımlı ve Bağımsız Değişken}

Araştırmada, öğrenme güçlüğü olan üç öğrenciye alışveriş yapmada kullanılan matematik problemlerini çözme becerisi doğrudan öğretim yöntemi ile öğretilmeye çalışılmıştır. Öğretimi yapılan problemler, öğrencilerin günlük hayatta alışveriş sırasında karşılaşabilecekleri durumlar göz önüne alınarak belirlenmiştir. Araştırmanın bağımlı değişkeni, katılımcı öğrencilerin alışveriş yapmada kullanılan işlemlerden oluşan matematik problemlerini çözme becerisini kazanma ve bu beceriyi günlük yaşama genelleme düzeyleridir. Çalışmaya katılan her öğrenci için 15 soruluk öğretim ve beş soruluk değerlendirmelerden oluşan öğretim setleri hazırlanmıştır. Öğretim setlerinde yer alan ilk beş soruda öğretim yapılmış, sonraki beş soruda rehberli uygulamalar gerçekleştirilmiş ve kalan beş sorunun öğrenci tarafindan bağımsız çözülmesi ve öğrencinin en az \%90 oranında başarı göstermesi beklenmiştir. Öğretim sona erdikten sonra toplu yoklama oturumlarında öğrenciye beş soruluk değerlendirme formu sunulmuştur. Katılımcı öğrencilerin dikkat süreleri göz önünde bulundurularak değerlendirme beş soruyla sınırlandırılmıştır. Öğrencilerin harfleri, sayıları ters yazma vb. biçimdeki yazım yanlışlarına yönelik herhangi bir müdahalede bulunulmamış, sadece problemleri doğru olarak çözmüş olmaları doğru tepki olarak kabul edilmiştir. $\mathrm{Bu}$ araştırmanın bağımsız değişkeni ise matematik problemlerini çcözmeyi öğretmek için kullanılan doğrudan öğretim yöntemidir.

\section{Deney Süreci}

Deney sürecini başlatmadan karş̧laşılabilecek olası aksaklıkları önceden belirleyebilmek ve gerekli önlemleri alabilmek için pilot uygulama oturumları gerçekleştirilmiştir. Bu oturumlarda, deney sürecinde öğretimi hedeflenmeyen iki farklı problem çözme becerisi üzerinde çalışılmıştır. Pilot çalışma katılımcılarla aynı özel eğitim ve rehabilitasyon merkezine devam eden ve benzer özelliğe sahip bir öğrenci ile gerçekleştirilmiştir. Pilot çalışmada elde edilen sonuçlara dayanarak öğretim süreci tekrar gözden geçirilerek düzenlenmiştir. Pilot çalışmada, öğretim oturumlarında ve değerlendirmede kullanılacak soru sayısı düzenlenmiştir. Ayrıca öğretime ve değerlendirmeye ayrılacak süre de pilot çalışma sonunda belirlenmiştir. Deney süreci, başlama düzeyi, öğretim, toplu yoklama, izleme ve genelleme oturumlarını içermektedir. Oturumların tamamında çalışmaya katılım davranışları ve öğretim oturumlarında verilen doğru tepkiler sürekli pekiştirme tarifesiyle sözel olarak (çok güzel, süper, aferin, harikasın gibi) pekiştirilmiştir.

\section{Yoklama Oturumları}

Yoklama oturumları toplu yoklama ve günlük yoklama olmak üzere iki şekilde gerçekleştirilmiştir. Toplu yoklama oturumları öğretime başlamadan önce ve her öğrencide ölçüt karşılandıktan sonra eş zamanlı olarak gerçekleştirilmiştir. Toplu yoklama oturumlarına ait veriler ardışı üç oturumda toplanmıştır. Her yoklama oturumunda beșer deneme gerçekleștirilmiștir. Toplu yoklama oturumlarının birincisi, öğretim oturumlarına başlamadan önce alınan başlama düzeyi verileri olarak, ikincisi, birinci öğrenciyle öğretim bittikten sonra, üçüncüsü, ikinci öğrenciyle öğretim bittikten sonra, dördüncü toplu yoklama oturumu ise üçüncü öğrenciyle öğretim bittikten sonra eşzamanlı olarak tüm katılımcılarla gerçekleştirilmiş̧ir. Günlük yoklama oturumları öğretim oturumlarının sonunda gerçekleş̧irilmiştir ve toplu yoklama oturumlarına benzer şekilde yürütülmüştür. Her günlük yoklama oturumu beş soru sorularak gerçekleştirilmiştir.

\section{Öğretim Oturumları}

Doğrudan öğretim yöntemi ile düzenlenen uygulamalar; model olma, rehberli uygulamalar ve bağımsız uygulamalardan oluşmaktadır. Model olma aşamasında öğretmen öğrenciye problemi nasıl çözmesi gerektiğini göstererek anlatır. Rehberli uygulamalar aşamasında öğretmen öğrencinin problemleri bağımsız bir şekilde çözmesini sağlamak için ipuçlarını yavaş yavaş geri çeker. Bağımsız uygulamalarda ise öğrencinin problemleri öğretmenin gösterdiği şekilde ve hiçbir ipucu almadan çözmesi beklenir. Öğretim oturumları her katılımcı için haftada iki gün ve günde tek oturum olarak düzenlenmiştir. Her bir öğretim oturumu yaklaşık 30 dakika sürmüştür. Öğretim oturumlarında iki basamaklı sayılarla toplama ve çıkarma, iki basamaklı sayıyı bir basamaklı sayıya bölme ve iki ile bir basamaklı sayıları çarpma işlemlerini gerektiren problemler sorulmuştur. Öğretim oturumlarında iki farklı türde problemler sunulmuştur. İlk problem türü çarpma ve çıkarma işlemini içerirken 
ikinci problem türü toplama ve bölme işlemini içermiştir. Uygulamada kullanılan tüm problemler aynı zorluk düzeyinde hazırlanmıştır.

\section{Model Olma Aşaması}

$\mathrm{Bu}$ aşamada uygulamacı öğrenciye bir problemi nasıl çözmesi gerektiğini göstermiştir. Uygulamac1 problemin olduğu çalışma kâğıdını öğrencinin görebileceği şekilde masaya koymuştur. Uygulamacının kendisi de işlemi kâğıt üzerinde öğrenciye model olacak şekilde çözmüștür. Bu aşamada uygulamacı önce öğrencinin problemi okuması için yönerge sunar ve öğrencinin problemi okumasını beklemiş̧ir Daha sonra problemde yer alan bilgileri sözel olarak öğrenciye aktarmış ve tahtaya yazmıștır. Tahta üzerinde problemin her adımını öğrenciye ipucu vererek çözmüş ve öğrenciden bulunan sonuçları uygulamacıyla birlikte sözel olarak tekrar etmesini beklemiştir. Model olma aşamasına ilişkin “Özlem'in 25 TL'si vardır. Babası Özlem'e 9 TL daha vermiștir. Özlem parasını kardeşiyle eşit olarak paylaşırsa kişi başına kaç TL para düşer?” problemi için Tablo 2'de bir örnek verilmiştir.

Tablo 2

Model Olma Aşaması

\begin{tabular}{|c|c|}
\hline Uygulamac1 & Öğrenci \\
\hline 1. "Problemi oku." & Öğrenci problemi okur. \\
\hline 2. “Özlem'in kaç TL'si var? 25” & 25 \\
\hline 3. "Babası Özlem'e kaç TL vermiş? 9" & 9 \\
\hline $\begin{array}{l}\text { 4. "Babası Özlem'e } 9 \text { TL daha verdiğine göre } 25 \text { ile 9'u toplamamız gerekiyor." } \\
\text { Uygulamacı tahtaya ' } 25+9 \text { =' yazar. Uygulamacı öğrencinin çözümü izleyip } \\
\text { izlemediğini gözlemler. }\end{array}$ & Öğrenci öğretmeni izler. \\
\hline 5. " 25 + 9 kaç eder?” & Öğrenci işlemi yapar. 34 der. \\
\hline 6. “Artık Özlem'in 34 TL'si var.” Çalışma kâğıdına işlemin sonucunu yazar. & Öğrenci ne yapar? \\
\hline $\begin{array}{l}\text { 7. "Şimdi Özlem parasını kardeşiyle paylaşmak istiyor. Parasını kaça bölmesi } \\
\text { gerekiyor?" Paylaşırken toplam miktar kişi sayısına bölünür. }\end{array}$ & Öğrenci 2 der. \\
\hline 8. “O zaman 34'ü 2'ye bölmemiz gerekiyor.” Öğretmen tahtaya işlemi yazar & Öğrenci öğretmeni izler. \\
\hline 9. “34 bölü 2 kaç eder?” & Öğrenci işlemi yapar ve 17 der. \\
\hline 10. “Evet. Özlem 34 TL'sini 2'ye böldüğünde her kardeșe 17 TL düşer." & \\
\hline
\end{tabular}

\section{Rehberli Uygulamalar Aşaması}

Rehberli uygulamalar aşamasında uygulamacı model olmak yerine öğrenciye sorular yönelterek işlemleri yapmasını istemiştir. Bu aşamada uygulamacı öğrencinin zorlandığı basamakları belirlemiştir ve öğrencinin yapamadığı basamaklar için tekrar model olarak öğrencinin öğrenmesini sağlamıştır. Rehberli uygulamalar aşamasında uygulamacı problemde yer alan verileri ögrenciye soru olarak yöneltir ve öğrencinin cevaplamasını bekler. Öğrencinin verdiği doğru tepki pekiştirilirken yanlış tepkiler öğretmen tarafından düzeltilir. Tablo 3 'te “Özlem'in 25 TL'si var. Babası Özlem'e 9 TL daha verdi. Özlem parasını kardeşiyle paylaşmak için ne yapmalıdır?" problemi için rehberli uygulamalar aşamasında ipucunun verildiği ve ipucunun azaltılmasına göre iki sunum örneği verilmiştir. Öğrenci bu aşamada $\% 80$ başarı ölçütünü karşıladığı zaman bağımsız uygulamalar aşamasına geçilmiştir. Öğrenci \% 80'in altında başarı gösterdiği zaman ise rehberli uygulamalar aşaması farklı bir soruyla tekrar edilmiştir.

\section{Bağımsız Uygulamalar Aşaması}

Rehberli uygulamalar aşamasından sonra, öğrenciden uygulamacının model olma aşamasında gösterdiği şekilde problemleri çözmesi beklenmiştir. Bu aşamada sorumluluk tamamen öğrencidedir. Bağımsız uygulamalar aşamasında uygulamacı herhangi bir ipucu sunmamış ve öğrenciden bağımsız bir şekilde problemi çözmesini beklemiştir. Bu aşamada öğrencilerden beş problemi çözmesi beklenmiş ve veriler kayıt formuna günlük yoklama oturumu verileri olarak kaydedilmiştir. 
Tablo 3

Rehberli Uygulamalar Aşaması

\begin{tabular}{|c|c|}
\hline \multicolumn{2}{|l|}{ Sunum 1} \\
\hline Uygulamacı & Öğrenci \\
\hline 1. "Problemi oku." & Öğrenci problemi okur. \\
\hline 2. “Özlem’in kaç TL’si var?” & 25 \\
\hline 3. "Babası Özlem’e kaç TL vermiş?” & 9 \\
\hline 4. "Babası Özlem'e para verdiğine göre burada ne yapmamız gerekiyor?" & 25 ile 9'u toplamamiz gerekiyor. \\
\hline 5. “O halde 25 ile 9'u topla." & Öğrenci toplama işlemini yapar. \\
\hline 6. “Özlem'in kaç TL’si oldu?” & 34 \\
\hline $\begin{array}{l}\text { 7. "Şimdi Özlem parasını kardeşiyle paylaşmak istiyor. Parayı kaç paya bölmesi } \\
\text { gerekiyor?" }\end{array}$ & 2 \\
\hline 8. “O zaman 34'ü 2'ye bölmemiz gerekiyor." & \\
\hline 9. "Şimdi ne yapman gerekiyor?" & Öğrenci bölme işlemini yapar. \\
\hline 10. "Her kardeşe kaç TL düşüyor?" & 17 \\
\hline \multicolumn{2}{|l|}{ Sunum 2} \\
\hline Uygulamac1 & Öğrenci \\
\hline 1. "Problemi oku." & Öğrenci problemi okur. \\
\hline 2. “Babası Özlem'e para verdikten sonra Özlem'in kaç TL'si olmuş?” & Öğrenci 25 ile 9'u toplar ve 34 der. \\
\hline $\begin{array}{l}\text { 3. "Şimdi Özlem parasını kardeşiyle paylaşmak istiyor. Parayı kaç paya bölmesi } \\
\text { gerekiyor?" }\end{array}$ & 2 \\
\hline 4. "O zaman ne yapmamız gerekiyor?" & 34'ü 2'ye bölmemiz gerekiyor. \\
\hline 5. “34'ü 2’ye böl.” & Öğrenci bölme işlemini yapar. \\
\hline 6. "Her kardeşe kaç TL para düşüyor?" & 17 \\
\hline
\end{tabular}

\section{İzleme ve Genelleme Oturumları}

İzleme oturumları her bir katılımcı için belirlenen ölçüt karşılandıktan bir, üç ve beş hafta sonra düzenlenmiştir. İzleme oturumlarında yoklama oturumlarında izlenen süreç izlenmiştir. Genelleme oturumları, öğretim ve izleme oturumlarından sonra düzenlenmiştir. Genelleme oturumlarında uygulamacı ve öğrenci süpermarkete gitmiştir. Katılımcı öğrencilerle üç genelleme oturumu düzenlenmiştir. Her bir oturumda beş deneme yapılmıştır. Uygulamacı öğrenciden ürün almasını ve kasaya giderek ödeme yapmasını istemiştir. Bu aşamada, öğrencinin ödemesi gereken miktarı ve para üstünü, uygulamacının ipucu sunmasını beklemeden hesaplaması beklenmektedir. Genelleme oturumlarında iki basamaklı sayılarla toplama ve çıkarma ve iki ile bir basamaklı sayıları çarpma işlemlerini gerektiren alışveriş durumları sunulmuştur. Örnek olarak öğrenci için 10 Türk Lirası olacak şekilde bütçe belirlenmiştir. Öğrenci iki adet çikolata bir adet de kek almıştır. İki adet çikolata 3 lira bir adet kek 1 liradır. Öğrenci kasaya geldiğinde ödemesi gereken miktarı hesaplamış ve ödemeyi yapmıştır. Daha sonra alması gereken para üstünü hesaplamış ve kasiyerin verdiği para üstüyle karşılaştırmıştır.

\section{Verilerin Toplanması ve Analizi}

Araştırma için Eskişehir Osmangazi Üniversitesi Sosyal ve Beşerî Bilimler Bilimsel Araştırma ve Yayın Etiği Kuruluna başvuru yapılmıştır. 30.11.2020 tarihli ve E-64075176-050.01.01-121441 sayılı yazı ile 13 Aralık 2020 tarihinde etik kurul izni alınmıştır. Araştırmanın tüm verileri 2018-2019 eğitim öğretim yılının bahar döneminde toplanmıştır. Araştırmanın etik kurul onayı geri dönük alınmıştır. Araştırmada etkililik, sosyal geçerlilik ve güvenirlik verisi olmak üzere üç tür veri toplanmıştır. Güvenirlik verileri dışında tüm veriler birinci yazar tarafından toplanmıştır.

\section{Etkililik Verilerinin Toplanmast ve Analizi}

Etkililik verilerinin toplanması için öğrencilerin doğru ve yanlış tepki sayıları kaydedilerek doğru tepki yüzdesi hesaplanmıştır. Etkililik verileri toplanırken "Günlük Yoklama Oturumları Veri Kayıt Formları" kullanılmıştır. Uygulamacı, her günlük yoklama oturumunda, öğrenciye önceden belirlenmiş alışveriş yapma hesaplarını içeren beș matematik problemi yöneltmiştir. Öğrenciden bu problemleri 20 dakikalık yanıt aralığ içinde çözmesi istenmiştir. Öğrencilerin matematik problemlerinin cevaplarını doğru bulması doğru tepki olarak kabul edilirken, cevapları yanlış bulması ya da soruyu boş bırakması yanlış tepki olarak kabul edilmiştir. 
Öğrencilerin doğru ya da yanlış cevapları herhangi dönüt ya da ipucu verilmeksizin veri kayıt formuna işaretlenerek kaydedilmiştir. Her oturumda farklı matematik problemleri kullanılmıştır. Oturum sonunda öğrencinin vermiş̧ olduğu doğru tepki sayısı, toplam soru sayısına bölünerek ve 100 ile çarpılarak doğru tepki yüzdesi hesaplanmıştır. Bulunan doğru tepki yüzdesi çizgi grafiği üzerinde gösterilmiştir.

\section{Sosyal Geçerlik Verilerinin Toplanması ve Analizi}

$\mathrm{Bu}$ araştırmada sosyal geçerlik verileri hem katılımcı öğrencilerin devam ettikleri özel eğitim ve rehabilitasyon merkezindeki destek eğitim öğretmenlerinden hem de katılımcı öğrencilerden toplanmıştır. Araştırmacılar, sosyal geçerlik verilerini toplamak için "Öğretmen Sosyal Geçerlik Formu" ve "Öğrenci Sosyal Geçerlik Formu" hazırlamıştır. Öğretmenler için hazırlanan formda; öğretilen becerinin önemi, günlük yaşamda kullanımı, yöntemin etkililiği ve öğretmenlerin araştırmada yer almayla ilgili memnuniyet durumu ile önerilerini belirlemeye yönelik 10 soru yer almaktadır. Öğrenciler için hazırlanan formlarda ise öğretilen beceriyi günlük yaşamlarında kullanıp kullanmadıklarını belirlemek amacıyla sorulan soruların yanı sıra araştırmada yer almadaki memnuniyet durumu, kullanılan yöntemi başka derslerde de kullanma isteği ve çalışmayla ilgili görüşlerini belirlemeye yönelik sorular yer almaktadır. Araştırma sona erdiğinde katılımcı öğrencilerle ve destek eğitim öğretmenleriyle birebir görüş̧me yapılmıştır. Görüşmeler, araştırmanın gerçekleştiği kurumda birinci araştırmacı tarafından yarı-yapılandırılmış olarak düzenlenmiştir. Yapılan görüşmeler ses kayıt cihazıyla kayıt altına alınmış ve görüşme sonrasında transkripti yapılmıştır. Görüşme sonrası katılımcı öğrenci ve destek öğretmenlerin verdikleri cevaplar betimsel analiz yöntemiyle analiz edilmiştir.

\section{Güvenirlik Verilerinin Toplanmast ve Analizi}

Araştırma süresince gözlemciler arası güvenirlik ve uygulama güvenirliği verisi olmak üzere iki tür güvenirlik verisi toplanmıştır. Araştırmanın gözlemciler arası güvenirlik ve uygulama güvenirliği verileri yüksek lisans tezinde doğrudan öğretim yöntemiyle matematik becerisi öğretimi yapan ve doktora eğitimine devam eden bir özel eğitim uzmanı tarafından toplanmıştır. Araştırma süresince düzenlenen tüm oturumların en az \%30'unda uygulama güvenirliği ve gözlemciler arası güvenirlik verisi toplanmıştır. Uygulamanın yapıldığı kurumda görüntü kaydı alınmasına izin verilmemesinden dolayı, araştırma süreci sadece ses kaydı alınarak kaydedilmiştir. Uygulama güvenirliği ve gözlemciler arası güvenirlik verileri yoklama ve öğretim oturumları için yansız atamayla belirlenmiş, oturumların ses kayıtlarııın ve çalışma sayfalarının incelenmesiyle toplanmıştır. Gözlemci, sunulan çalışma sayfalarında yer alan soru çözümlerini incelemiş, uygulama sırasında alınan ses kaydını dinleyerek uygulama güvenirliği formunu doldurmuştur. Araştırmacının gözlemciler arası güvenirlik verilerinin analizinde "Görüş birliği / (Görüş birliği + Görüş ayrıllığı) x 100" formülü kullanılırken, uygulamacı güvenirliği verilerinin analizinde Gözlenen uygulamacı davranışı/ Planlanan uygulamacı davranışı) x 100" formülü kullanılmıştır (Erbaş, 2012). Araştırmanın gözlemciler arası güvenirliği $\% 100$ olarak belirlenirken uygulama güvenirliği \%98 olarak hesaplanmıştır.

\section{Etkililik Bulguları}

\section{Bulgular}

$\mathrm{Bu}$ araştırmada öğrenme güçlüğ̈̈ olan katılımcı öğrencilerin matematik problemlerini çözme becerisini kazanma, kazandıkları beceriyi sürdürme ve günlük hayatta alışveriş yapmada kullanma düzeylerine yönelik elde edilen veriler Şekil 1'de gösterilmektedir. Şekil 1'de yer alan çizgi grafiğinde, dikey eksende her bir oturumdaki doğru tepki yüzdesi, yatay eksende ise araştırmada yapılan oturum sayısı gösterilmektedir. Çizgi grafiğinde, başlama düzeyi, uygulama, toplu yoklama, izleme ve genelleme verileri yer almaktadır. Çalışmada bir başlama düzeyi oturumu, üç toplu yoklama oturumu, üç uygulama oturumu gerçekleştirilmiştir.

Araştırmanın birinci katılımcısı Burak'ın, öğretim öncesi başlama düzeyi evresinde gösterdiği performansın ortalaması $\% 0$ olarak hesaplanmıştır. Burak, öğretim sunulduğu sırada gerçekleştirilen günlük yoklama oturumlarının birincisinde $4 / 5$, takip eden dört oturumda ise $5 / 5$ düzeyinde performans sergilemiştir. Üst üste üç oturumda $\% 90$ ve üzeri başarı gösterdiği için Burak ile uygulama evresi sonlandırılmıştır. Burak'ın son üç oturumunda gösterdiği kararlı verilerin ortalaması \%100 olarak hesaplanmıştır. Öğretim sonrası uygulanan birinci toplu yoklama evresinde verilerin ortalaması $\% 93$, ikinci toplu yoklama evresinde ise verilerin ortalaması $\% 100$ olarak belirlenmiştir. Burak, uygulama sonra erdikten sonra yapılan izleme oturumlarında da \%100 başarı göstermiştir.

Araştırmanın ikinci katılımcısı Kerem'in, öğretim öncesi başlama düzeyi evresinde sergilediği performansın ortalaması $\% 0$ 'dır. Kerem'in birinci toplu yoklama oturumunda da gösterdiği performans $\% 0$ olarak 
hesaplanmıştır. Kerem, öğretim sunulduğu sırada gerçekleştirilen günlük yoklama oturumlarının ilkinde $4 / 5$ takip eden dört oturumda ise $5 / 5$ düzeyinde performans sergilemiştir. Üst üste üç oturumda $\% 90$ ve üzeri başarı gösterdiği için Kerem ile uygulama evresi sonlandırılmıştır. Kerem'in son üç oturumunda gösterdiği kararlı verilerin ortalaması \%100 olarak hesaplanmıştır. Öğretim oturumları sonrasında yapılan toplu yoklama oturumunda Kerem'in başarı ortalaması \%100 olarak hesaplanmıştır. Veriler Kerem'in öğretim bittikten bir, iki ve üç hafta sonra da beceriyi sürdürdüğünü göstermektedir.

Araştırmanın son katılımcısı Mehmet'in, öğretim öncesi başlama düzeyi evresindeki performansının ortalamas $1 \% 0$ olarak hesaplanmıştı. Mehmet gerçekleştirilen birinci ve ikinci toplu yoklama oturumlarının her ikisinde de $\% 20$ başarı sağlamıştır. Mehmet'e öğretim sunulduğu sırada gerçekleştirilen günlük yoklama oturumlarından birincisinde $4 / 5$, takip eden dört oturumda ise $5 / 5$ düzeyinde performans sergilemiştir. Üst üste üç oturumda $\% 90$ ve üzeri başarı gösterdiği için Mehmet ile uygulama evresi sonlandırılmıştır. Mehmet'in son üç oturumunda gösterdiği kararlı verilerin ortalaması $\% 100$ olarak hesaplanmıştır. Veriler Mehmet' in öğretim bittikten bir, iki ve üç hafta sonra beceriyi sürdürdüğünü göstermektedir.

\section{Genelleme Bulguları}

Burak, Kerem ve Mehmet'in öğrendikleri matematik problemi çözme becerilerini günlük yaşama genellemelerine ait bulgular Şekil 1'de yer almaktadır. Her üç katılımcı öğrenci başlama düzeyi oturumlarında problem çözme konusunda $\% 0$ başarı gösterdikleri için bu beceriyi günlük yaşamlarında da kullanamadıkları varsayılmıştır. Öğretimin ardından öğretimi yapılan problemlerin içerdiği işlemlerin kullanılması gereken durumlar bir markette oluşturulmuş ve öğrencilerin hesap yapması beklenmiştir. Öğretim sonra erdikten sonra markette yapılan genelleme oturumlarında her üç katılımcı öğrenci de $\% 100$ başarı sergilemişlerdir. Şekil 1 incelendiğinde, katılımcı öğrencilere doğrudan öğretim yöntemiyle yapılan problem çözme öğretimi sonucunda elde edilen kazanımların, günlük yaşama da genellenebildiği görülmektedir.

\section{Sosyal Geçerlik Bulguları}

Sosyal geçerlik verilerinin toplanması için hazırlanan formları üç öğrenci ve iki öğretmenle yapılan görüşmeler doğrultusunda doldurulmuştur. Çalışmada yer alan tüm katılımcı öğrenciler ve destek eğitim öğretmenleri, çalışılan konunun önemli olduğunu ve öğrenilen becerinin günlük hayatta sıklıkla kullanıldığını belirtmişlerdir. Ayrıca tüm katılımcı öğrenciler çalışmada bulunmaktan memnun olduklarını belirtmişlerdir. Öğretmenlerden biri çalışmada yer almaktan mutlu olduğunu diğeri ise mutlu olduğunu ancak çalışma nedeniyle öğrencilerin normal programlarındaki derslerinin aksadığını aktarmıştır. Çalışmada yer alan tüm öğrenciler bu yöntemin diğer derslerinde de kullanılması gerektiğini belirtirken öğretmenlerden bir tanesi yöntemin ismini duyduğunu ama bu kadar sistematik işlendiğini bilmediğini, bundan sonra diğer derslerde de kullanacağını söylemiştir. Diğer öğretmen de yöntemin etkililiğini bildiği için hâlihazırda diğer derslerinde de kullandığını aktarmıştır. Sosyal geçerlik verilerinin toplandığı tüm katılımcılar araştırma sürecinin oldukça eğlenceli ve olumlu geçtiğini vurgulamıştır. Çalışmanın olumlu yönleri; eğlenceli, aktif, işlevsel ve günlük yaşama yardımcı olarak sıralanmıştır. Araştırmada olumsuz yön olarak sadece bir öğretmen, çalışma sürecinin uzun olduğunu belirtmiştir. Olumsuz görüş belirten öğretmen bu görüşünü "Biz burada ögrrencimle haftada iki saat ders yapabiliyoruz. Çalışma da birkaç hafta sürdüğ̈̈ için bana çok uzun geldi" olarak aktarmıştır. 


\section{Şekil 1}

Katılımcıların Problem Çözmeye Yönelik Doğru Tepki Yüzdeleri (BD: Başlama Düzeyi, TY: Toplu Yoklama)

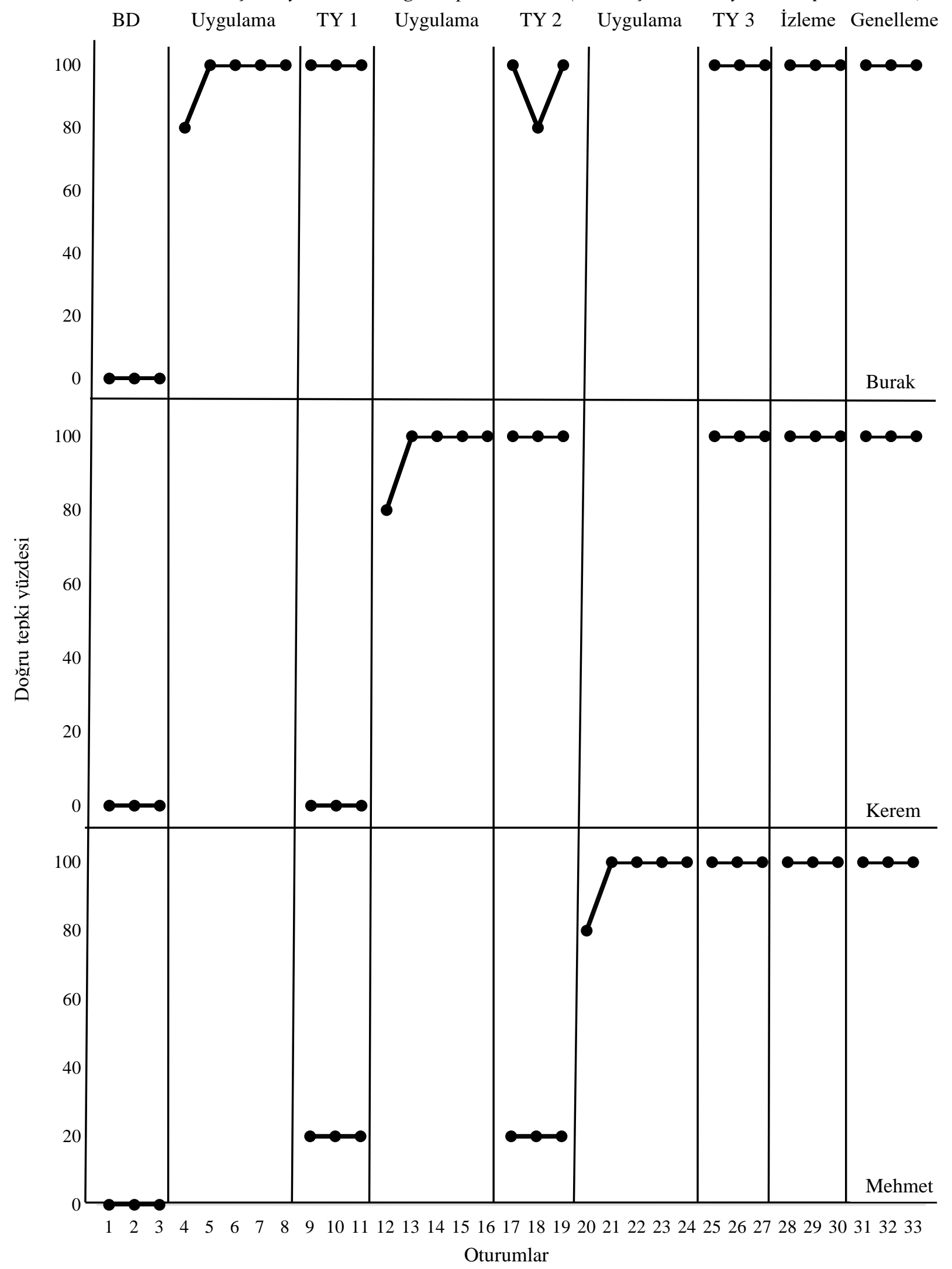




\section{Tartışma}

$\mathrm{Bu}$ araştırmanın temel amacı, öğrenme güçlüğü olan öğrencilere alışveriş hesaplarını içeren matematik problemlerinin çözümünü doğrudan öğretim yöntemi kullanarak ögretmek ve bu becerileri günlük hayatlarına genelleyip genelleyemediklerini incelemektir. Araştırmanın sonuçları, doğrudan öğretim yöntemiyle sunulan öğretimin sonunda öğrenme güçlüğü olan öğrencilerin alışveriş yapmada kullanılan işlemleri içeren matematik problemlerini çözme becerisini kazandıklarını, beceriyi ögrretim sona erdikten sonra sürdürdüklerini ve beceriyi günlük yaşamda alışveriş yaparken kullandıklarını göstermektedir.

Araştırmanın birinci alt sorusuna yönelik bulgular incelendiğinde, doğrudan öğretim yönteminin genel eğitim okullarında öğrenim gören öğrenme güçlüğü olan öğrencilere alışveriş yapmada kullanılan matematik problemlerini çözme becerisini kazandırmada etkili olduğu görülmüştür. Uygulama öncesinde tüm katılımcıların matematik problemi çözme performansları \%0 olarak belirlenmişken uygulama sonunda her üç katılımcının da performansları \%100 düzeyine ulaşmıştır. Araştırmanın bu bulgusu, alanyazında öğrenme güçlüğü olan öğrencilere problem çözme becerisinin öğretiminde doğrudan öğretim yönteminin kullanıldığı diğer araştırmaların bulgularıla benzerlik göstermektedir (Cass vd., 2003; Jitendra \& Hoff, 1996; Jitendra vd., 2002; Preston, 2016; Small, 2011; Zawaiza \& Gerber, 1993). Ülkemizdeki matematik eğitim programlarının tüm kademelerinde problem çözme becerisine yönelik kazanımlar bulunmaktadır. Buna karşın ulusal alanyazında genel eğitim okullarında kaynaştırma eğitimine devam eden öğrenme güçlüğü olan öğrencilere matematik problemi çözmeyi öğretmeyi amaçlayan çalışmaların sınırlı olduğu görülmektedir. Özellikle genel eğitim öğretmenlerinin sıklıkla kullandıkları öğretim yöntemi (Akbaş, 2004) olan doğrudan öğretim yönteminin kullanılmasıyla öğrenme güçlüğü olan öğrencilere matematik problemi çözme becerisini kazandırmaya yönelik bir çalışmaya rastlanmamıştır. Bu çalışmada öğrenme güçlüğü olan öğrencilere hem doğrudan öğretim yöntemiyle matematik problemi çözme becerisi kazandırılmaya çalıșılmış hem de kazanılan bu beceriyi alışveriş yapmada kullanmaları sağlanmıştır. Ulusal ve uluslararası alanyazında doğrudan öğretim yöntemiyle kazandırılan matematik problemi çözme becerisinin günlük yaşama genellemesinin yapıldığı bir araştırmaya rastlanmamıştır. Bu çalışma ayrıca problem çözme becerisinin öğretiminde doğrudan öğretim yönteminin kısa sürede olumlu sonuçlar ortaya çıkardığını göstermektedir. Katılımcılar beş oturum sonunda \%100 başarı düzeyine ulaşmıştır. Bu bulgu diğer çalışmaların bulgularıyla benzerlik göstermektedir (Cass vd., 2003; Jitendra vd., 2002; Preston, 2016; Small, 2011). Bu sonuç matematik problemlerinin öğretiminde doğrudan öğretim yönteminin hızlı ve etkili sonuç verdiğini doğrulamaktadır.

Araştırmanın ikinci alt sorusuna yönelik bulgulara bakıldığında tüm katılımcıların performanslarını uygulamadan sonra bir, iki ve üç hafta sonra da sürdürdüğü görülmektedir. Araștırmanın bu bulgusu, ulusal ve uluslararası alanyazında öğrenme güçlüğü olan öğrencilere problem çözme becerisinin öğretiminde doğrudan öğretiminin kullanıldığı önceki çalışmalarla benzerlik göstermektedir (Cass vd., 2003; Jitendra \& Hoff, 1996; Jitendra vd., 2002; Small, 2011). Zhang (2017) tarafından yapılan çalışmada, öğrenme güçlüğü yaşayan çocuklara geometri problemlerini çözmeye yönelik doğrudan öğretim yöntemiyle uygulanan müdahalenin sona ermesinin ardından öğrencilerin kazandıkları becerileri sürdürdükleri belirlenmiştir. Jitendra ve Hoff (1996), öğrenme güçlügü olan öğrencilerle sözel problem çözme performansları üzerinde şemaya dayalı doğrudan öğretim stratejisinin etkilerini inceledikleri çalışmada, etkinin araştırma sona erdikten 2-3 hafta sonra devam ettiğini ortaya koymuşlardır. Doğrudan öğretimde öğretimin ilk aşamalarında tüm sorumluluk öğretmendeyken sonraki aşamalarında sorumluluk yavaş yavaş öğretmenden öğrenciye geçmektedir. Buradaki amaç öğrenciyi kazandırılan beceride bağımsız hale getirmektir (Dağseven, 2001; Güzel, 1998). Bu çalışmada katılımcılar öğrendikleri beceriyi öğretim sonlandırıldıktan sonra da korumuşlardır. Doğrudan öğretim yönteminin son aşaması olan öğrenciyi bağımsız hale getirme, yapılan bu araştırmayla desteklenmektedir. Doğrudan öğretim yöntemi kullanılarak kazandırılan matematik problemi çözme becerisinin öğretimin sona ermesinden sonra sürdürülebilir olması, öğrencilerin hem daha sonra karşılaşacakları matematik konularını ögrenmelerine hem de günlük yaşamlarına katkı sağlayabilecektir.

Araştırmanın üçüncü alt sorusuna ait bulgulara bakıldığında ise tüm katılımcıların kazandıkları beceriyi günlük yaşamlarına genelleyebildikleri gözlemlenmiştir. Uygulama öncesi öğrencilerin problem çözme becerilerinde $\% 0$ başarı gösterdiği göz önüne alındığında, günlük yaşamlarında da problem çözme konusunda güçlük yaşadıkları varsayılmıştır. Uygulama sonunda ise tüm katılımcılar \%100 başarıyla beceriyi günlük yaşamlarına genelleyebilmiştir. Öğrenme güçlüğü olan öğrencilere yönelik matematik problemi çözme becerisinin öğretildiği çalışmalar incelendiğinde, matematik problemlerinin günlük yaşama genellenmesine yönelik bir araştırmaya rastlanmamıştır. Tipik gelişim gösteren öğrenciler gibi öğrenme güçlüğü olan öğrencilerin de toplumda bağımsız yaşamaları beklenir ve eğitimleri bu amaca katkı sağlayacak şekilde düzenlenir.

Tipik gelişim gösteren öğrenciler birçok beceriyi kendiliğinden öğrenme yoluyla edinebilirken öğrenme güçlüğü olan öğrenciler çeşitli becerileri gelişim özelliklerine ve performans düzeylerine uygun öğretim programlarıyla kazanabilmektedirler (Özsoy vd., 2001). Alanyazında öğrenme güçlüğü olan öğrencilere pek çok matematik becerisinin kazandırıldığı ancak bu becerilerin günlük yaşama genellenmesinin yapılmadığı görülmektedir. Oysa kazanılan 
becerinin günlük yaşamda kullanılması hem becerinin genellenmesini hem de kalıcılığını arttıracaktır. Tüm özel gereksinimi olan öğrenciler gibi öğrenme güçlüğü olan öğrencilerin bağımsız yaşamlarını desteklemek için parayı nasıl harcamaları gerektiğinin öğretilmesi önemli ve gereklidir. Dolayısıyla bu araştırmadan elde edilen bulgular, öğrenme güçlügü olan öğrencilerin bağımsız yaşam becerilerini arttırma amacıyla günlük yaşamda gereksinim duyabilecekleri becerilere ilişkin öğretim yapılmasının olumlu sonuçlar ortaya koyabileceğini göstermesi açısından da önemlidir.

Araştırmanın dördüncü alt sorusuna yönelik bulgular incelendiğinde ise araştırmada yer alan katılımcı öğretmenlerin ve öğrencilerin araştırmaya ilişskin olumlu görüşlere sahip oldukları görülmektedir. Bu bulgu alanyazında yer alan doğrudan öğretim yöntemi kullanılarak yapılan matematik becerisi öğretimi çalışmalarıyla benzerlik göstermektedir (Cass vd., 2003; Jitendra \& Hoff, 1996; Kot \& Yı1kmış, 2018). Katılımcı öğrencilerin tamamı bu yöntemin diğer derslerde de kullanılması gerektiğini belirtirken, özel eğitim öğretmenleri de yöntemin son derece etkili olduğunu belirtmişlerdir. Katılımcı özel eğitim öğretmenleri doğrudan öğretim yöntemini derslerinde kullandıklarını ancak araştırmadaki gibi sistematik takip etmediklerini belirtmişlerdir. Bu açıdan düşünüldüğünde etkili bir öğretim yönteminin sistematiğinin gözlemlenmesi de sosyal açıdan oldukça önemlidir. Katılımcı öğrenciler ve özel eğitim öğretmenleri çalışılan konunun son derece önemli olduğunu belirtirken, öğrenciler sıklıkla günlük yaşamlarında bu sorunla karşı karşıya kaldıklarını dile getirmiştir. Bu bulgu Baki (2004) tarafından yapılan çalışmanın sosyal geçerlik bulgusuyla benzerlik göstermektedir. Araştırmaya katılan öğretmenler hem kullanılan yöntem hem de genellenebilirlik açısından çalışmanın önemli olduğunu aktarmış ve olumlu görüş bildirmişlerdir. Bu görüşler dikkate alındığında, yapılan araştırmanın sosyal açıdan son derece önemli olduğu düşünülmektedir. Yapılan yarı-yapılandırılmış görüşmede bir katılımcı öğretmen çalışmanın uzun sürdüğünü ve derslerini aksattığını belirtmiştir. Öğrenme güçlüğü olan öğrenciler, rehabilitasyon merkezlerinde haftada iki saat bireysel eğitim almaktadırlar. Çalışmanın uygulama, izleme ve genelleme oturumlarının birkaç hafta sürmesi ve öğrencilerle haftada iki saat uygulama yapılabilmesi göz önüne alındığında katılımcı öğretmenin bu nedenlerden dolayı çalışmayı uzun olarak nitelendirdiği düşünülmektedir.

Araştırmadan elde edilen bulgular doğrultusunda, bu araştırmanın şu açılardan önem taşıdığı söylenebilir; (1) Araştırma bulguları genel eğitim sınıflarında öğrenim gören öğrenme güçlüğü olan öğrencilere matematik problemlerinin öğretiminde, öğretilen becerinin kalıcılığının sağlanmasında ve becerinin günlük yaşama genellenmesinde doğrudan öğretim yönteminin etkili olduğunu göstermektedir. (2) Öğrenme güçlüğü olan öğrencilerin dikkat sürelerinin ve odaklanmalarının sınırlı olması göz önüne alındığında kullanılan doğrudan öğretim yönteminin öğretmen tarafından basamak basamak sunulmasından dolayı öğrencilerin dikkat ve odaklanma güçlüklerinin üstesinden geldiği görülmektedir. Ayrıca yöntemde kullanılan öğretim materyallerinin, öğretmen sunumunun açık ve net olması ve öğrencinin gereksinimi olduğu kadar deneme yapılması öğrencilerin öğrenme düzeyini ve özgüvenini arttırmaktadır. (3) $\mathrm{Bu}$ araştırma doğrudan öğretim yönteminin problem çözme ve günlük yaşama genellenmesini ortaya koyan ilk araştırma niteliğini taşımaktadır. Bu genelleme ayrıca öğrenilen becerinin kalıcı olmasına da yarar sağlamaktadır.

Doğrudan öğretim yöntemiyle sunulan matematik problemlerini çözme becerisinin öğretiminin gerçekleştiği bu araştırmada etkililiğe ilişkin bulguların doğruluk düzeyinin yüksek olması ve katılımcı öğrenci ve öğretmenlerin çalışmaya ilişkin görüşlerinin olumlu olmasına karşın bazı sınırlı yönler de bulunmaktadır. Bunlardan ilki araştırmanın tanısı öğrenme güçlüğü olan üç öğrenciyle sınırlandırılmış olmasıdır. İkinci olarak problemler öğrencilerin alışverişte karşılaşabilecekleri işlemleri içerecek şekilde sınırlandırılmıştır. Ayrıca araştırma öğrenme güçlüğü olan öğrencilerin genel eğitim okullarındaki doğal ortamları yerine yapılandırılmış bir ortamda gerçekleştirilmiştir. Araştırmada genelleme için ön test yapılmaması ve uygulamanın video kayıt altına alınmaması da sınırlılıklar arasında gösterilebilir. $\mathrm{Bu}$ sınırlılıklar doğrultusunda yapılan çalışmanın genellenebilirliğini ve uygulanabilirliğini arttırmak için uygulamaya ve ileride yapılacak araştırmalara yönelik bazı önerilere yer verilebilir.

Uygulamaya yönelik alanda çalışan öğretmenlere problem çözme becerisinin yanında başka matematik konuları ve diğer akademik derslerin öğretimi yapılırken doğrudan öğretim yöntemini kullanmaları ve öğrendikleri becerileri günlük yaşamda kullanmaları konusunda öğrencilerini desteklemeleri önerilebilir. Özel gereksinimi olan öğrencilerin parayı kullanma becerilerini geliştirmek için araştırma farklı yöntem ve katılımcı grubuyla yinelenebilir. İleride yapılacak araştırmalarda ise matematik problemlerinin farklı yöntemler kullanılarak öğretilmesi ve günlük yaşam için işlevsel olan becerilerin seçilmesi önerilmektedir. Son olarak ileri araştırmalarda öğrencilerin ailelerinden de sosyal geçerlik verileri toplanarak aileler açısından da sosyal kabul edilebilirliği araştırılabilir.

\section{Yazarların Katkı Düzeyleri}

Samed Yenioğlu çalışmanın konusunu belirleme, araştırma desenine karar verme, veri toplama, verilerin analizi ve çalışmanın raporlanması görevlerinde yer almıştır. Kübra Sayar çalışmanın konusunu belirleme, araştırma desenini belirleme ve çalışmanın raporlanması görevlerinde yer almıştır. Nevin Güner-Yıldız çalışmanın konusunu belirleme, araştırma desenini belirleme ve çalışmanın raporlanması görevlerinde yer almıştır. 


\section{Kaynaklar}

Akbaş, O. (2004). Türk milli eğitim sisteminin duyuşsal amaçlarının ilköğretim II. kademede gerçekleşme derecesinin değerlendirilmesi [Evaluation of the degree of reaching of affective goals at the elementery level in Turkish national education system] (Tez Numarası: 190366) [Doktora tezi, Gazi Üniversitesi]. Yükseköğretim Kurulu Ulusal Tez Merkezi.

Albert, L. R., \& Antos, J. (2000). Daily journals connect mathematics to real life. Mathematics Teaching in the Middle School, 5(8), 526-531. https://doi.org/10.5951/mtms.5.8.0526

Altun, M. (2000). İlköğretimde problem çözme öğretimi [Teaching problem solving in primary education]. Milli Ĕgitim Dergisi, 147(3), 27-33.

Altun, M. (2016). Illkokullarda matematik ögrretimi [Teaching mathematics in primary schools] (20. bask1). Alfa Aktüel Yayınları.

Arı, A., Deniz, L., \& Düzkantar, A. (2010). Özel gereksinimli bir öğrenciye toplama ve çıkarma işlem süreçlerinin öğretiminde eşzamanlı ipucuyla öğretimin etkililiği [The effectiveness of simultaneous prompting procedure on teaching addition and subtraction operations to a mentally handicapped child]. Abant İzzet Baysal Üniversitesi Eğitim Fakültesi Dergisi, 10(1), 48-67. https://dergipark.org.tr/tr/pub/aibuefd/issue/1498/18124

Artut, P. D., \& Tarım, K. (2006). İlköğretim öğrencilerinin rutin olmayan sözel problemleri çözme düzeylerinin, çözüm stratejilerinin ve hata türlerinin incelenmesi [Investigation of the elementary school students' problem solving levels, problem solving strategies and error types in the nonroutine word problems]. Çukurova Üniversitesi Sosyal Bilimler Enstitüsü Dergisi, 15(2), 39-50.

Bağlama, B. (2018). Zihin yetersizliği olan öğrencilere matematik problem çözme becerisinin öğretiminde doğrudan öğretim yöntemiyle sunulan bilgisayar destekli video ile model olma öğretiminin etkililiği [Effectiveness of computer supported video modeling presented with direct instruction method on teaching mathematical problem solving skills to students with intellectual disability] [Doktora tezi, Yakın Doğu Üniversitesi]. http://docs.neu.edu.tr/library/6686846107.pdf

Baki, K. (2014). Şemaya dayall ögrretim stratejisinin zihinsel yetersizliği olan ögrrencilerin matematikte sözel problem çözme becerilerine etkililiği [The effects of schema-based strategy instruction on the mathematical word problem solving skills of students with intellectual disabilty] (Tez Numaras1: 375309) [Yüksek lisans tezi, Anadolu Üniversitesi]. Yükseköğretim Kurulu Ulusal Tez Merkezi.

Bouck, E. C., \& Flanagan, S. (2009). Assistive technology and mathematics: What is there and where can we go in special education. Journal of Special Education Technology, 24(2), 17-30. https://doi.org/10.1177/016264340902400202

Browder, D. M., \& Grasso, E. (1999). Teaching money skills to individuals with mental retardation: A research review with practical applications. Remedial and Special Education, 20(5), 297-308. https://doi.org/10.1177/074193259902000506

Bryant, D. P., Bryant, B. R., \& Hammill, D. D. (2000). Characteristic behaviors of students with LD who have teacher-identified math weaknesses. Journal of Learning Disabilities, 33(2), 168-177. https://doi.org/10.1177/002221940003300205

Carnine, D., Silbert, J., Kameenui, E. J., \& Tarver, S. G. (1997). Direct instruction reading. Merrill.

Cass, M., Cates, D., Smith, M., \& Jackson, C. (2003). Effects of manipulative instruction on solving area and perimeter problems by students with learning disabilities. Learning Disabilities Research \& Practice, 18(2), 112-120. https://doi.org/10.1111/1540-5826.00067

Cooper, J. O., Heron, T. E., \& Heward, W. L. (2019). Applied behavior analysis (3rd ed.). Pearson Prentice Hall. 
Dağseven, D. (2001). Zihinsel engelli öğrencilere temel toplama ve saat okuma becerilerinin kazandırlması, sürekliliği ve genellenebilirliğinde, doğrudan ve basamaklandırllmış ögretim yaklaşımlarına göre hazırlanan öğretim materyalinin farklllaşan etkililiğgi [The effectiveness of instructional materials that were designed according to direct instruction and interactive unit in acquization, maintanence and generelization of addition and telling time skills in students with mental retardation] (Tez Numaras1: 108833) [Yüksek lisans tezi, Gazi Üniversitesi]. Yükseköğretim Kurulu Ulusal Tez Merkezi.

Dağseven-Emecen, D. (2008). Zihinsel yetersizlikten etkilenmiş ögrencilere sosyal becerilerin kazandırılmasında doğrudan öğretim ve bilişsel süreç yaklaşımları ile yapılan öğretimin etkililiklerinin ve verimliliklerinin karşllaştırlması [The comparison of effectiveness and efficiency of direct instruction and problem solving approachs in teaching of social skills for children with mental retardation] (Tez Numaras1: 219032) [Doktora tezi, Gazi Üniversitesi]. Yükseköğretim Kurulu Ulusal Tez Merkezi.

Erbaş, D. (2012). Bilimsel araştırmalarda güvenirlilik. E. Tekin-İftar (Ed.), Eğitim ve davranış bilimlerinde tekdenekli araştırmalar [Within single-subject research in education and behavioral sciences] içinde (ss. 217-254). Türk Psikologlar Derneği Yayınları.

Freeman-Green, S. M., O'Brien, C., Wood, C. L., \& Hitt, S. B. (2015). Effects of the SOLVE strategy on the mathematical problem solving skills of secondary students with learning disabilities. Learning Disabilities Research \& Practice, 30(2), 76-90. https://doi.org/10.1111/ldrp.12054

Gainsburg, J. (2008). Real-worlds connections in secondary mathematics classrooms. Journal of Mathematics Teacher Education, 11(3), 199-219. https://doi.org/10.1007/s10857-007-9070-8

Gobadze, T., \& Düzkantar, A. (2019). Özel eğitimde matematik ile ilgili yapılan çalışmaların incelenmesi [Investigation of regarding mathematics education studies in special education] Journal of Gifted Education and Creativity, 6(2), 147-165https://dergipark.org.tr/en/download/article-file/801706

Güzel, R. (1998). Alt özel sinıflardaki öğrencilerin sesli okudukları öyküyü anlama becerilerini kazanmalarında doğrudan ögretim yöntemiyle sunulan bireyselleştirilmiş okuduğunu anlama materyalinin etkililiği [The effectiveness of the individualized reading comprehension material offered by direct instruction method on the ability of students in subspecific classes to acquire the ability to tell stories they read aloud.] (Tez Numarasi: 73975) [Doktora tezi, Gazi Üniversitesi]. Yükseköğretim Kurulu Ulusal Tez Merkezi.

Hunt, J. H., \& Vasquez, E. (2014). Effects of ratio strategies intervention on knowledge of ratio equivalence for students with learning disability. The Journal of Special Education, 48(3), 180-190. https://doi.org/10.1177/0022466912474102

Jitendra, A. K., DiPipi, C. M., \& Perron-Jones, N. (2002). An exploratory study of schema-basedword-problem solving instruction for middle school students with learning disabilities: An emphasis on conceptual and procedural understanding. The Journal of Special Education, 36(1), 23-38. https://doi.org/10.1177/00224669020360010301

Jitendra, A. K., \& Hoff, K. (1996). The effects of schema-based instruction on the mathematical word-problem solving performance of students with learning disabilities. Journal of Learning Disabilities, 29, 422-431. https://doi.org/10.1177/002221949602900410

Karabulut, A., \& Yıkmış, A. (2016). Zihin engelli bireylere saat söyleme becerisinin öğretiminde eşzamanlı ipucuyla öğretimin etkililiği. Abant İzzet Baysal Üniversitesi Ĕgitim Fakültesi Dergisi, 10(2), 103-113. https://dergipark.org.tr/en/download/article-file/16708

Karabulut, A., Yıkmış, A., Özak, H., \& Karabulut, H. (2015). Şemaya dayalı problem çözme stratejisinin zihinsel yetersizliği olan öğrencilerin problem çözme performanslarına etkisi [The effect of schema based problem solving strategy on problem solving performance of students with intellectual disabilities]. Abant İzzet Baysal Üniversitesi Eğitim Fakültesi Dergisi, 15(Özel Say1), 243-258. https://dergipark.org.tr/tr/download/article-file/17153 
Karakoç, T. (2002). Görme engelli ögrrencilere matematikte sözlü problem çözümünün öğretiminde doğrudan ögretim yaklaşımına göre hazırlanan ögretim programının akranlar aracılı̆̆ıyla sunulmasının etkililiğ $i$ [The effectiveness of the peer-to-peer presentation of the curriculum prepared according to the direct teaching approach in teaching the verbal problem solving in mathematics to visually impaired students] (Tez Numarasi: 113248) [Yüksek lisans tezi, Gazi Üniversitesi]. Yükseköğretim Kurulu Ulusal Tez Merkezi.

Kingsdorf, S., \& Krawec, J. (2014). Error analysis of mathematical word problem solving across students with and without learning disabilities. Learning Disabilities Research \& Practice, 29(2), 66-74. https://doi.org/10.1111/ldrp.12029

Kot, M., \& Yıkmış, A. (2018). Zihin yetersizliği olan öğrencilere problem çözme becerisinin öğretiminde şemaya dayalı ögretim stratejisinin etkisi [The effects of schema-based instruction on the mathematical problem solving skills of children with mental retardation]. Kalem Eğitim ve İnsan Bilimleri Dergisi, 8(2), 335358. https://doi.org/10.23863/kalem.2019.107

Kroesbergen, E. H., \& Van Luit, J. E. H. (2003). Mathematics interventions for children with special educational needs: A meta-analysis. Remedial and Special Education, 24(2), 97-114. https://doi.org/10.1177/07419325030240020501

Mechling, L. C., Gast, D. L., \& Barthold, S. (2003). Multimedia computer-based instruction to teach students with moderate intellectual disabilities to use a debit card to make purchases. Exceptionality, 11(4), 239-254. https://doi.org/10.1207/S15327035EX1104_4

Miller, S., \& Mercer, C. (1997). Education aspects of mathematics disabilities. Journal of Learning Disabilities, 30(1), 47-56. https://doi.org/10.1177/002221949703000104

Millî Eğitim Bakanlığı [Ministry of National Education]. (2018). Matematik dersi öğretim programı (Illkokul ve ortaokul 1, 2, 3, 4, 5, 6, 7 ve 8. sinfflar) [Mathematics lesson curriculum (Primary and secondary school 1st, 2nd, 3rd, 4th, 5th, 6th, 7th and 8th grades)]. http://mufredat.meb.gov.tr/Dosyalar/201813017165445MATEMATIK\%20ÖĞRETIM\%20PROGRAMI\%202018v.pdf

Montague, M., \& Applegate, B. (1993). Mathematical problem solving characteristics of middle school students with learning disabilities. Journal of Special Education, 27(2), 175-201. https://doi.org/10.1177/002246699302700203

National Council of Teachers of Mathematics. (2000). Principles and standarts for school mathematics. NCTM.

Olkun, S., \& Toluk, Z. (2009). Illköğretimde etkinlik temelli matematik öğretimi [Activity-based mathematics teaching in primary education] (4. baskı). Maya Akademi.

Ostad, A., \& Sorensen, P. M. (2007). Private speech and strategy-use patterns: Bidirectional comparisons of children with and without mathematical difficulties in a developmental perspective. Journal of Learning Disabilities, 40(1), 2-14. https://doi.org/10.1177/00222194070400010101

Özkubat, U., Karabulut, A., \& Sert, C. (2021). Öğrenme güçlüğü olan ortaokul öğrencilerine uygulanan matematik problemi çözme müdahaleleri: Kapsamlı alanyazın incelenmesi [Math problem solving interventions for middle school students with learning disabilities: A comprehensive literature review]. Ankara Üniversitesi Eğitim Bilimleri Fakültesi Özel Eğitim Dergisi, Erken Görünüm. https://doi.org/10.21565/ozelegitimdergisi.774650

Özkubat, U., \& Özmen, E. R. (2018). Öğrenme güçlüğü olan öğrencilerin matematik problemi çözme süreçlerinin incelenmesi: Sesli düşünme protokolü uygulaması [Analysis of mathematical problem solving process of students with learning disability: Implementation of think aloud protocol]. Ankara Üniversitesi Eğitim $\begin{array}{lllll}\text { Bilimleri Fakültesi Özel Eğitim } & \text { Dergisi, } & 19(1), & \text { 155-180. }\end{array}$ https://doi.org/10.21565/ozelegitimdergisi.299494

Özsoy, Y., Özyürek, M., \& Eripek, S. (2001). Özel eğitime giriş [Introduction to special education] (11. bask1). Karatepe Yayinları.

Preston, A. I. (2016). Effects of Singapore model method with explicit instruction on math problem solving skills of students at risk for or identified with learning disabilities [Unpublished doctoral dissertation]. The University of North Carolina at Charlotte. 
Rosenzweig, C., Krawec, J., \& Montague, M. (2011). Metacognitive strategy use of eighth-grade students with and without learning disabilities during mathematical problem solving: a think-aloud analysis. Journal of Learning Disabilities, 44(6) 508-520. https://doi.org/10.1177/0022219410378445

Shin, M., \& Bryant, D. P. (2015). A synthesis of mathematical and cognitive performances of students with mathematics learning disabilities. Journal of Learning Disabilities, 48(1), 96-112. https://doi.org/10.1177/0022219413508324

Small, H. H. (2011). The effects of direct instruction in teaching addition and subtraction of decimals and decimal word problems on students at risk for mathematics failure [Unpublished master's thesis, Utah State University]. http://digitalcommons.usu.edu/etd/1020

Sparrow, L. (2008). Real and relevant mathematics: Is it realistic in the classroom? Australian Primary Mathematics Classroom, 13(2), 4-8.

Swanson, H. L., \& Jerman, O. (2006). Math disabilities: A selective meta-analysis of the literature. Review of Educational Research, 76(2), 249-274. https://doi.org/10.3102/00346543076002249

Tekin-İftar, E. (2012). Çoklu yoklama modelleri. E. Tekin-İftar (Ed.), Eğitim ve davranış bilimlerinde tek-denekli araştırmalar [Within single-subject research in education and behavioral sciences] içinde (ss. 217-254). Türk Psikologlar Derneği Yayınları.

Tufan, S., Tiryaki, D., \& Altunay-Arslantekin, B. (2020). Zihinsel yetersizliği olan öğrencilere tam saatleri ayırt etme becerisinin öğretiminde doğrudan öğretim modelinin etkililiği [Effectiveness of direct instruction model on teaching identification of full hours to students with intellectual disabilities]. Ankara Üniversitesi Eğitim Bilimleri Fakültesi Özel Eğitim Dergisi, 21(4), 757-787. https://doi.org/10.21565/ozelegitimdergisi.595152

Tuncer, A. T. (2009). Şemaya dayalı sözlü matematik problemi çözme stratejisinin görme yetersizliği olan öğrencilerin sözlü problem çözme performanslarına etkisi [The effects of schema based word problem solving strategy on problem solving performance of students with visual impairment]. Eğitim ve Bilim, 34(153), 183-197. http://egitimvebilim.ted.org.tr/index.php/EB/article/view/583

Xin, Y. P., Grasso, E., Dipipi-Hoy, C. M., \& Jitendra, A. (2005). The effects of purchasing skill instruction for individuals with developmental disabilities: A meta-analysis. Exeptional Children, 71(4), 379-400. https://journals.sagepub.com/doi/pdf/10.1177/001440290507100401

Yantır, N. (2007). İlköğretim matematik öğretmenliği öğrencilerinin işbirlikçi öğrenme yöntemiyle geometri dersine ilişkin erişi düzeylerinin belirlenmesi [To set access level of geometry lesson with cooperative learning at primary maths schoolteaching students] (Tez Numarası: 211585) [Yüksek lisans tezi, Dokuz Eylül Üniversitesi]. Yükseköğretim Kurulu Ulusal Tez Merkezi.

Zawaiza, T. R. W., \& Gerber, M. M. (1993). Effects of explicit instruction on math word-problem solving by community college students with learning disabilities. Learning Disability Quarterly, 16(1), 64-79. https://doi.org/10.2307/1511159

Zhang, D. (2017). Effects of visual working memory training and direct instruction on geometry problem solving in students with geometry difficulties. Learning Disabilities: A Contemporary Journal, 15(1), 117-138. https://files.eric.ed.gov/fulltext/EJ1141989.pdf 


\section{Ankara University Faculty of Educational Sciences Journal of Special Education}

2022, 23(3), 613-636
RESEARCH

Recieved Date: 15.12 .20

Accepted Date: 22.11.21

OnlineFirst: 12.01 .22

\title{
Teaching the Skills of Solving Shopping Problems and Generalizing to Daily Life to Students with Learning Disabilities
}

\author{
Samed Yenioğlu
}

\author{
Kübra Sayar ${ }^{(D)} 2$
}

\begin{abstract}
Introduction: Mathematics skills are frequently needed in daily life. The importance of mathematics in daily life necessitates the acquisition of basic mathematical skills by all individuals, including those with special needs. In particular, teaching the concept of money and how to spend money is very important for students with special needs to survive without being dependent on others. In this study, the effectiveness of education given by using direct instruction on the ability of students with learning difficulties in general education schools to acquire the ability to solve mathematical problems consisting of transactions used in shopping and to use this skill while shopping in daily life was examined.
\end{abstract}

Method: This research was designed according to the multiple probe design with probe conditions across participants. Participants of the research consist of three male students between the ages of 10-12 who continue their education through inclusion in public schools in Eskisehir and receive support from a special education and rehabilitation center.

Findings: In the study, the participants were taught the ability to solve mathematical problems consisting of operations used while shopping with direct instruction method, and the level of using the skills learned by the participants while shopping in a market was evaluated. According to the findings obtained as a result of the research, the participant students gained the ability to solve problems involving the processes used in shopping and were able to generalize this skill to their daily lives by using them in grocery shopping.

Discussion: The findings of the study are consistent with the results of the studies in the literature that examine the teaching of mathematics skills to students with special needs. The obtained results were compared with similar studies and discussed.

Keywords: Shopping skills, daily life skills, problem solving, mathematics teaching, direct instruction method, learning disability.

To cite: Yenioğlu, S., Sayar, K., \& Güner-Yıldız, N. (2022). Teaching the skills of solving shopping problems and generalizing to daily life to students with learning disabilities. Ankara University Faculty of Educational $\begin{array}{llll}\text { Sciences Journal of Special } & \text { Education, }\end{array}$ https://doi.org/10.21565/ozelegitimdergisi.841368

\footnotetext{
${ }^{1}$ Corresponded Author: Specialist, Eskişehir Osmangazi University, E-mail: samedyenioglu@gmail.com, https://orcid.org/0000-0002-2227-9132

${ }^{2}$ Specialist, Eskişehir Osmangazi University, E-mail: kubrasayar87@ gmail.com, https://orcid.org/0000-0003-0901-3660

${ }^{3}$ Assoc. Prof., Eskişehir Osmangazi University, E-mail: antreh@gmail.com, https://orcid.org/0000-0002-9135-6429
}

Yenioğlu et al. 


\section{Introduction}

Mathematic skills are frequently encountered in daily life. Mathematics is needed in learning time, shopping, working life, and even in games played by children (Bouck \& Flanagan, 2009; Gobadze \& Düzkantar, 2019). For this reason, math skills are needed to be learned for independent living (Tufan et al., 2020). When the goals of the primary and secondary school mathematics curriculum are examined, it is seen that there are basic aims such as reasoning, communicating using mathematical language, making predictions, understanding mathematical concepts, and using them in daily life (Ministry of National Education [MoNE], 2018). The mathematical skills included in the curriculum are interconnected and prerequisite skills of each other. Problemsolving skills are also among the main goals of the mathematics curriculum (National Council of Teachers of Mathematics [NCTM], 2000). Problem-solving is an important mathematical skill that requires students to put many concepts and skills in the mathematics curriculum into practice (Bağlama, 2018). In the process of problemsolving, the ability to understand mathematical information such as numbers, symbols and signs, and to establish relationships between these information develops (Yantır, 2007). With the development of problem-solving skills, children improve their creative and critical thinking skills, and learn to use analysis, synthesis, and mathematical thinking skills (Olkun \& Toluk, 2009). Children who gain mathematical skills notice patterns and schemes in their daily lives and learn concepts and scientific processes more easily (Olkun \& Toluk, 2009). Mathematical thinking skill has an important place in the life of children with typical development as well as children with special educational needs [SEN] (Karabulut \& Y1kmış, 2016). The main aim of education is to provide individuals with the skills necessary for independent living (Cooper et al., 2019), and for individuals with SEN who need more intense and sensitive support than their typically developing peers it is more important and necessary to gain math skills.

Mathematics skills are one of the main areas that need to be intervened in students with learning disabilities, who are included in the group that needs special education (Miller \& Mercer, 1997). Students with learning disabilities have difficulties in recognizing numbers, writing numbers, performing basic operations, and general mathematical terms (Bryant et al., 2000; Kingsdorf \& Krawec, 2014). In addition, the difficulties experienced by students with learning disabilities in reading and reading comprehension skills leads to confusion in understanding mathematical terms such as adding, subtracting, or borrowing, which are included in mathematical problems (Özkubat \& Özmen, 2018). Because the primary goal of education is to improve the skills of every individual at the highest level, as is the case for students with learning disabilities, the problem-solving process is also very important in the education of these individuals (Kot \& Y1kmış, 2018). Problem-solving skill, which is one of the basic mathematics areas, is one of the skills that students with learning disabilities need supportive education (Montague \& Applegate, 1993). There are many studies who reveal the difficulties that students with learning disabilities experience while solving problems (Montague \& Applegate, 1993; Ostad \& Sorensen, 2007; Özkubat \& Özmen, 2018; Rosenzweig et al., 2011; Shin \& Bryant, 2015; Swanson \& Jerman, 2006). It is observed that students with learning disabilities have difficulty in problem-solving skills, especially in the processes related to the presentation of the problem and in determining strategies. These strategies include restating the problem in their own words, visualizing the problem on paper with pictures, and creating plans to solve the problem. For this reason, teaching problem-solving skills to students with learning disabilities should include clear instruction (Montague \& Applegat, 1993). During the teaching of mathematics problems, teaching sharing, grouping, time reading, and shopping skills can also be done. Teaching the concept of money and how to spend money is very important for these individuals to live without being dependent on others (Ar1 et al., 2010; Browder \& Grasso, 1999). Using money while shopping is a skill area that requires problem-solving skills as well as basic operations skills (Mechling et al., 2003). Since individuals with SEN have more difficulty when learning abstract and complex mathematical skills than their peers (Bouck \& Flanagan, 2009; Kroesbergen \& Van Luit, 2003), effective teaching methods and techniques that include concretization and dividing the process into small steps while teaching mathematical problem-solving skills should be used.

It is seen that different methods and strategies are used in intervention studies to improve the mathematical problem-solving skills of students with learning disabilities. Some of the methods and strategies used in these studies can be listed as direct instruction, schema-based problem-solving strategy, concrete-semi-concrete-abstract strategy, and SOLVE strategy (Özkubat et al., 2021). For example, Zawaiza and Gerber (1993) stated in one of the studies using direct instruction that direct instruction improves verbal mathematics problem solving skills in students with learning disabilities. In another study, Preston (2016) revealed the effectiveness of direct instruction in teaching one-step math problems to students with learning disabilities. In addition, it was determined that students could generalize the acquired skill to homework and other problems solved in the classroom. In another 
study, Small (2011) determined that direct instruction was effective in teaching verbal mathematics problem solving to students with mathematical learning disabilities. In addition to using the direct instruction as a standalone method, it is seen that this method is presented with a different strategy in some studies. For example, Jitendra and Hoff (1996) examined the effectiveness of the schema-based teaching strategy presented with direct instruction on the problem-solving skills of three primary school students with learning disabilities. The results of the study showed that there was an increase in the rate of solving the problems of all students. Cass et al. (2003) used direct instruction and concrete-semi-concrete-abstract strategy in teaching circumference and field problems to students with learning disabilities. Researchers revealed that as a result of the intervention, students quickly acquired the skill, maintained this skill for two months, and transferred the acquired skills to a problem-solving format using paper and pencil. Considering the studies in which students with learning disabilities were taught mathematics problem solving skills with another method as direct instruction, Jitendra et al. (2002) examined the effects of schema-based problem-solving strategy on the development of mathematical problem-solving skills with middle school students with low performance in mathematics. As a result of the study, it was found that all participants improved their math problem-solving skills, maintained these skills and generalized the strategies they learned to different types of problems. In addition, in the study conducted by Freeman-Green et al. (2015), the effects of the SOLVE strategy, a reminder-based learning strategy designed to help middle school students with learning disabilities in solving mathematical word problems, on mathematical problem-solving skills were examined. As a result of the research, it was observed that there was an increase in the number of correct answers of all participants. In addition, it was found that the students generalized the strategy they learned to other mathematical topics. In international literature, the problem-solving skills of students with learning disabilities have been developed using different methods and strategies. In the studies, generalization sessions were limited to generalizing the acquired skill to different problems. There was no research, in which the problem-solving skills of the students was generalized to daily life.

In Turkey, there is a limited number of studies in which students with SEN are taught mathematical problem-solving skills. In these studies, students with visual impairment have been taught mathematical problemsolving skills through direct instruction method and schema-based problem-solving strategy (Karakoç, 2002; Tuncer, 2009). In another study in which direct instruction and the schema-based teaching strategy were used together, the effect of the strategy on the math problem-solving performance of students with intellectual disability attending secondary school was investigated. As a result of the study, it was observed that the strategy was effective and that the participants were able to generalize the acquired skill to different environments and materials and preserve it after 20 days (Kot \& Y1kmış, 2018). In Turkey, there is no intervention study in which direct instruction or other methods/strategies are used in order to support the mathematical problem-solving skills of students with learning disabilities and to enable them to generalize the acquired skills into their daily lives.

No study in both national and international literature has examined the generalization of problem-solving skills to daily life. However, it is necessary to solve mathematical problems in many areas of our lives such as while using money, sharing, and ratio-proportion problems (Browder \& Grosso, 1999). For this reason, it is very important to teach mathematics problem solving in connection with daily life. In the literature, it is stated that students generally see mathematics independently from their lives and cannot see the benefits of mathematics in daily life (Gainsburg, 2008; Sparrow, 2008). It may be necessary to carry out the acquisition phase of teaching in a structured environment at the beginning, but it is reported in the literature that performing this teaching in connection with daily life yields better results (Xin et al., 2005). In studies, it is emphasized that associating mathematics teaching with daily life causes students to better understand mathematical concepts and increase their attitude and motivation towards mathematics (Albert \& Antos, 2000; Gainsburg, 2008).

In this study, it was tried to improve the mathematical problem-solving skill of students with learning disabilities by using direct instruction. Direct instruction was preferred in this study because it is easy to apply, provides students with independent application opportunity, helps to organize and generalize the skills they have acquired (Carnine et al., 1997; Dağseven-Emecen, 2008). There are few studies in the national and international literature in which the mathematics problem-solving skills of students with learning disabilities were tried to improve (Bağlama, 2018; Baki, 2014; Karabulut et al., 2015; Kot \& Y1kmış, 2018; Preston, 2016; Small, 2011). There is no study which examines if these students could generalize their acquired mathematical problem-solving skill to their daily life. This study will contribute to the field, as it is the first study in which mathematics problems are taught to students with learning disabilities, as well as the acquired skill is generalized to daily life. The main purpose of this study is to examine the ability of students with learning disabilities to gain the ability to solve 
mathematical problems involving the operations used while shopping and to use these skills in daily life. For this purpose, answers to the following questions were sought:

1. When students with learning disabilities are taught to solve mathematics problems consisting of operations used while shopping with direct instruction, can students gain the skill?

2. Can the participating students maintain the acquired skills after one, two and three weeks?

3. Can the participating students generalize their mathematical problem-solving skills to their daily shopping?

4. Is this research socially applicable to students with learning disabilities and their teachers?

\section{Method}

\section{Research Model}

This study, which examines the ability to gain mathematical problem-solving skills of students with learning disabilities, who are placed in a public school and generalizing these skills to daily life, was designed according to the multiple probe design with probe conditions across participants. In this design, baseline data are obtained from all participants simultaneously before the instruction, and when stable data is obtained, the teaching sessions are started in the first participant. When the first participant meets the criteria, a first full probe session is held for all participants. After the stable data is obtained, the second participant starts the teaching session. When the second participant also meets the criterion, a second full probe session is held with all participants. After the stable data is obtained, teaching with the third participant is started and when the third participant meets the criterion, the last full probe session is conducted with all participants and the application is terminated (TekinIftar, 2012).

\section{Participants}

It was expected that the students, who participate in this study would continue their education in an inclusive setting and do not have a visual-hearing impairment. They are expected to have prerequisite skills, such as having expressive language skills, being able to direct attention on the stimulus for at least five minutes, having the ability to follow instructions, being able to read and write, being able to read and write numbers, recognizing money, being able to add two-digit numbers and two-digit numbers with carry, being able to subtract a two-digit number from a two-digit number without and with breaking, being able to multiply a two-digit number with a onedigit number, and being able to divide a two-digit number by a one-digit number. To determine if the participants have the prerequisite skills, students' teachers, who give supportive education at a rehabilitation center, were interviewed. Three male students who are placed in a public school in Eskisehir and receiving supportive education in a special education and rehabilitation center participated in this study. All participants have a learning disability according to their health reports.

\section{Researchers}

The first author of the study graduated from the Special Education Department of Mentally Handicapped Education undergraduate program, completed his master's degree in Special Education, and continues his doctorate education in the same field. The first author who carried out the applications in the research has more than three years of experience in special education teaching. The second author of the study, on the other hand, graduated from the Special Education Department of the Mentally Handicapped Teacher Education undergraduate program and also received a master's degree in Special Education. The researcher has a one-year special education teaching experience. The third author of the study has a Ph.D. in Special Education and works as a lecturer in the special education department at a university in Central Turkey.

\section{Setting}

The research was carried out in a special education and rehabilitation center where the participants received supportive education. All the teaching sessions took place in the Special Learning Disabilities Individual2 class in the rehabilitation center. In this classroom, there are two tables, three chairs, two bookshelves, a storage cabinet, a whiteboard fixed to the wall, and books. The generalization sessions of the research were held in a supermarket near the special education and rehabilitation center. There are food, beverage, greengrocer, butcher, delicatessen, and stationery departments in the supermarket. 


\section{Dependent and Independent Variable}

The dependent variable of the study is the level of students' ability to solve mathematical problems consisting of operations used while shopping and the level of generalization this skill to daily life. Teaching sets consisted of 15 questions (for each phase of direct instruction; modeling, guided application, and independent phase, five questions were prepared) and five question were used for evaluation phase. The criterion in the research is that the student achieves at least $90 \%$ success. Considering the attention span of the students with learning disabilities, the evaluation was limited to five questions. No intervention was made to students for the spelling mistakes in form of writing letters or numbers wrong. Only solving the problems correctly was accepted as the correct response. The independent variable of this research is the direct teaching method.

\section{Intervention process}

Pilot implementation sessions were held in order to determine the possible malfunctions that may be encountered before starting the experimental phase and to take the necessary measures. In these sessions, two different problem-solving skills, which were not intended to be taught during the experimental phase, were taught. Based on the results of the pilot study, the teaching process was revised and reorganized. The number of questions to be used in the teaching and evaluation sessions was arranged. In addition, the time to be devoted to teaching and evaluation was determined at the end of the pilot study. The experimental phase includes baseline, training, probe, maintenance and generalization sessions. In all sessions, participants' on-task behaviors and correct responses in the teaching sessions were reinforced verbally (like well done, very good, wonderful) with the continuous reinforcement schedule. Training sessions were carried out in one-to-one instructional arrangements in a special education and rehabilitation center. Generalization sessions were held in a supermarket.

Training sessions consisted of modeling, guided practice and independent practice phases. In the modeling phase, the teacher taught the student how to solve the problem. During the guided practice phase, the teacher gradually withdrew the clues to enable the student to solve the problems more independently. In the independent practice phase, the student was expected to solve problems without giving any clues. Teaching sessions were organized for each participant two days a week and one session a day. Probe sessions were conducted in two ways, including intermittent and daily probe sessions. Intermittent probe sessions were held simultaneously before starting teaching and after meeting the criteria for each student. Daily probe sessions were held at the end of the teaching sessions.

Maintenance sessions were held one, three and five weeks after the criteria were met in each teaching set. It was held like the probe sessions. In the generalization sessions, the practitioner and the student went to the supermarket. The implementer asked the student to buy the product and pay by going to the cash desk. At this stage, the student is expected to calculate the amount to be paid and the amount of money without waiting for the practitioner to present a tip. In generalization sessions, shopping situations requiring addition and subtraction with two-digit numbers, dividing a two-digit number by one-digit number and multiplying two and one-digit numbers were presented.

Three types of data were collected in the study: effectiveness data, social validity data, and reliability data. An application was made to Eskisehir Osmangazi University Social and Human Sciences Scientific Research and Publication Ethics Committee for the research. Ethics committee approval was obtained on 13 December 2020 with the letter dated 30.11.2020 and numbered E-64075176-050.01.01-121441. In this study, social validity data were collected from both students and supportive education teachers. At the end of the study, one-on-one interviews were conducted with the students and supportive education teachers. During the research, two types of reliability data were collected: inter-observer reliability and application reliability data. The inter-observer agreement (IOA) and treatment integrity data of the study were collected by a research assistant who held undergraduate and postgraduate degrees in special education and was a PhD student in the same field. IOA and treatment integrity data were collected for at least $30 \%$ of all sessions held during the research, were determined by unbiased assignment for probe and teaching sessions and were collected by examining the audio recordings of the sessions and worksheets. Treatment integrity data were collected separately for probe and teaching sessions.

\section{Results}

In the study, three baseline sessions, probe sessions, three maintenance sessions, and three generalization sessions were conducted. The average performance of the first participant (Burak), in the baseline phase was calculated as $0 \%$. Burak performed $4 / 5$ in the first session of the daily probe sessions and $5 / 5$ in the following four sessions. The training phase with Burak was terminated because he achieved $90 \%$ and above success in three 
consecutive sessions. The average of the data was $93 \%$ in the first probe phase after the training, and $100 \%$ in the second probe phase and maintenance sessions. The average performance of the second participant (Kerem), in the baseline phase and in the first probe session was calculated as $0 \%$. Kerem performed 4/5 in the first session of the daily probe sessions and 5/5 in the following four sessions. The training phase was terminated with Kerem because he achieved $90 \%$ and above success in three consecutive sessions. In the probe session held after the teaching sessions, Kerem's average success was calculated as $100 \%$. The data show that Kerem maintains the skill one, two and three weeks after the end of the training. The average performance of Mehmet, the last participant of the research, in the baseline phase was calculated as $0 \%$, and the average performance in the first and second full probe sessions was $20 \%$. Mehmet performed $4 / 5$ in the first session of the daily probe sessions and $5 / 5$ in the following four sessions. The training phase was terminated with Mehmet because he achieved $90 \%$ and above success in three consecutive sessions. The data show that Mehmet maintains the skill one, two and three weeks after the training phase.

It was assumed that all three participating students showed $0 \%$ success in problem solving in the baseline sessions, so they could not use this skill in their daily lives. All three participating students achieved $100 \%$ success in the generalization sessions held in the market after the instruction ended.

All students and supportive education teachers stated that the subject studied is important and the acquired skill is frequently used in daily life. All participants said that the research process was very enjoyable and positive. One negative aspect of the study was that only one teacher stated that the training phase took too long.

\section{Discussion}

The main purpose of this study was to teach students with learning disabilities to solve mathematical problems consisting of operations used while shopping using direct instruction and to determine whether they can generalize these skills to their daily lives. The results of the study reveal that direct instruction was effective in the acquisition of mathematical problem-solving skills of the students with learning disabilities, maintenance and generalization of these skills. The findings of the study are similar to the results of the studies in which direct instruction was used to improve the mathematics skills of students with SEN.

The findings for the first question of the study revealed that direct instruction was effective in improving the mathematical problem-solving skills of students with learning disabilities. These findings of the study are similar to the findings of other studies in the literature where direct instruction was used in teaching mathematics skills to students with SEN (Cass et al., 2003; Jitendra \& Hoff, 1996; Jitendra et al., 2002; Preston, 2016; Small, 2011; Zawaiza \& Gerber, 1993). Although problem-solving skills are important, only a few studies exist in which mathematical problem-solving skills are taught to students with SEN. In this study, students with learning disabilities were trained to solve mathematical problems consisting of operations used while shopping and to use these skills while shopping in a supermarket. No research has been found in national and international literature in which the acquired mathematical problem-solving skills were generalized to daily life. This study also showed that direct instruction produces positive results in a short time in teaching problem solving skills. Participants reached $100 \%$ success level at the end of five sessions. This finding is like the findings of other studies (Cass et al., 2003; Jitendra et al., 2002; Preston, 2016; Small, 2011). This result reveals once again that direct instruction gives fast and effective results in teaching mathematical problems.

The findings for the second question of the study showed that all participants maintained their performance one, two and three weeks after the training. This finding of the study is similar to previous studies in which direct instruction was used in teaching mathematics subjects to students with SEN (Cass et al., 2003; Jitendra \& Hoff, 1996; Jitendra et al., 2002; Small, 2011). In a study conducted by Zhang (2017), it was determined that after the implementation through direct instruction students with learning disabilities learned how to solve geometry problems and maintained the acquired skills. In the early stages of direct instruction, the teacher has the responsibility, while later the responsibility gradually passes from the teacher to the student. The aim here is to help the student in using the acquired skill independently (Dağseven, 2001; Güzel, 1998). In this study, the participants maintained the skills they learned after the training was ended. Making the student independent in the acquired skills, which is the last stage of the direct instruction, is supported by this research. The maintenance of the mathematical problem-solving skill after the end of the training will contribute to learning the mathematical subjects they will encounter later and their daily lives.

The findings of the third question, showed that all participants were able to generalize the skills they gained to their daily lives. Like individuals with typical development, individuals with learning disabilities are 
expected to live independently in the society and their education is organized to contribute to this purpose. While students with typical development can acquire many skills through spontaneous learning, students with learning disabilities sometimes need teaching programs that are suitable for their development characteristics and performance levels. In the literature, it is seen that many skills are taught to students with learning disabilities, but many skills are not generalized to daily life. However, using the acquired skill in daily life will increase both the generalization and maintenance of the skill. It is especially important and necessary to teach students with learning disabilities how to spend money to support their independent lives.

The findings for the fourth question revealed that the special education teachers and students have positive opinions about the research. This finding is similar to the studies of teaching mathematics skills using direct instruction (Cass et al., 2003; Jitendra \& Hoff, 1996; Kot \& Yıkmış, 2018). While all the students stated that this method should be used in other lessons, special education teachers also stated that the method was extremely effective. Students and special education teachers stated that the subject of the research was extremely important, and students stated that they frequently face this problem in their daily lives. These findings are like the social validity findings of the study conducted by Baki (2004). The teachers who participated in the study stated that the study was important in terms of both the method used and generalizability and expressed a positive opinion. Considering these views, it is thought that the research conducted is extremely important from a social point of view. In the semi-structured interview, a participant teacher stated that the training took too long, and it disrupted his lessons. Students with learning disabilities receive two hours of supportive education per week in rehabilitation centers. Because the training, maintenance and generalization sessions of the study take a few weeks and the students had only two hours a week, it is thought that the participant teacher described the study as long for these reasons.

In line with the findings obtained from the research, it can be said that this research is important in terms of; (1) Research findings show that direct instruction is effective in teaching mathematics problem-solving skills to students with learning disabilities, providing the maintenance of the acquired skills and generalizing these skills to daily life. (2) Considering the limited attention span and focus of students with learning disabilities, it is seen that the students overcome their attention and focus difficulties since the direct instruction is presented step by step by the teacher. (3) This research is the first to reveal the generalization of problem-solving skills to daily life. This generalization also helps the acquired skills to be maintained.

Although the effectiveness, maintenance, generalization, and social validity findings are high, there are some limitations of this study. First of all, the participants of the study were only three students with learning disabilities. Secondly, the problems are limited with operations students may encounter in shopping. In addition, the research was carried out in a structured environment rather than a natural environment in general education schools. Finally, there was no pre-test for generalization, and the implementation was not video-recorded. In line with these limitations, some suggestions for future research can be given.

Teachers working in the field can be advised to support their students in using the direct instruction in teaching other mathematical and other academic subjects, as well as using problem-solving skills in daily life. Research can be repeated with different methods and groups of participants to improve the ability of students with SEN to use money. In future studies, it is recommended to teach mathematical problems using different methods and to select skills that are functional for daily life. At the same time, the effectiveness of this method on different types of disabilities can be examined. Finally, social validity data can be collected from the families of the students.

\section{Authors' Contributions}

Samed Yenioğlu took part in determining the subject of the manuscript, research design, data collection, data analysis and reporting of the study. Kübra Sayar took part in determining the subject of the manuscript, research design and reporting of the study. Nevin Güner-Yıldız took part in determining the subject of the manuscript, research design and reporting of the study. 